Q

Cipdates

Cite as

Nano-Micro Lett.

(2021) $13: 171$

Received: 27 April 2021

Accepted: 13 July 2021

Published online: 9 August 2021

(C) The Author(s) 2021

\section{High-Defect-Density Graphite for Superior-Performance Aluminum-Ion Batteries with Ultra-Fast Charging and Stable Long Life}

\author{
Jisu Kim ${ }^{1}$, Michael Ruby Raj $^{1}$, Gibaek Lee ${ }^{1 凶}$
}

\title{
HIGHLIGHTS
}

- Surface-modified graphite (acid-treated expanded graphite (AEG)/base-etched graphite (BEG)) displays an abundant micro- to nanosized pores/defects and exposed edge graphitic site.

- AEG and BEG exhibit high specific capacity, rate capability and cyclic stability compared with pristine graphite.

- High defect density of BEG electrode exhibits profound effect on the chloroaluminate anions intercalation kinetics.

\begin{abstract}
Rechargeable aluminum-ion batteries (AIBs) are a new generation of low-cost and large-scale electrical energy storage systems. However, AIBs suffer from a lack of reliable cathode materials with insufficient intercalation sites, poor ion-conducting channels, and poor diffusion dynamics of large chloroaluminate anions $\left(\mathrm{AlCl}_{4}{ }^{-}\right.$ and $\mathrm{Al}_{2} \mathrm{Cl}_{7}{ }^{-}$). To address these issues, surfacemodified graphitic carbon materials [i.e., acidtreated expanded graphite (AEG) and base-etched
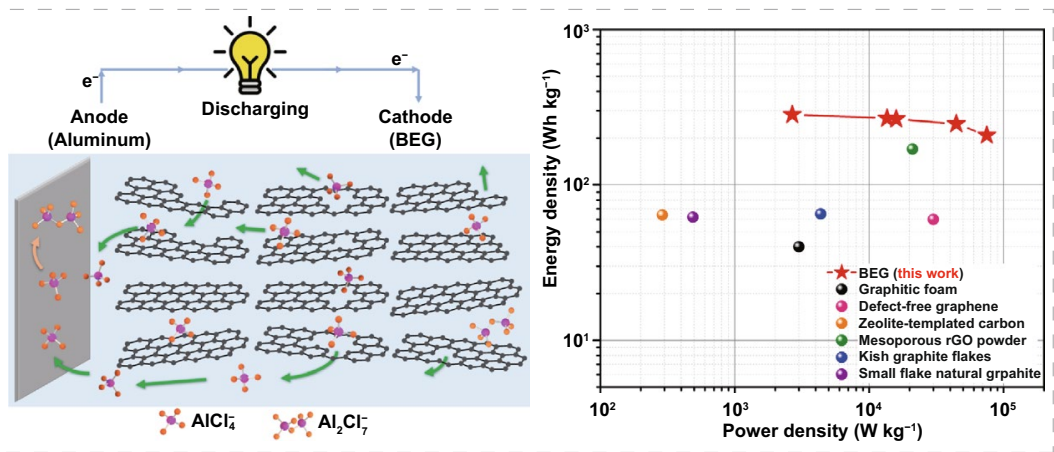

graphite (BEG)] are developed as novel cathode materials for ultra-fast chargeable AIBs. AEG has more turbostratically ordered structure covered with abundant micro- to nano-sized pores on the surface structure and expanded interlayer distance $\left(d_{002}=0.3371 \mathrm{~nm}\right)$ realized by surface treatment of pristine graphite with acidic media, which can be accelerated the diffusion dynamics and efficient $\mathrm{AlCl}_{4}{ }^{-}$ions (de)-intercalation kinetics. The AIB system employing AEG exhibits a specific capacity of $88.6 \mathrm{mAh} \mathrm{g}^{-1}\left(4 \mathrm{~A} \mathrm{~g}^{-1}\right)$ and $\sim 80 \mathrm{mAh} \mathrm{g}^{-1}$ at an ultra-high current rate of $10 \mathrm{~A} \mathrm{~g}^{-1}$ ( 99.1\% over 10,000 cycles). BEG treated with KOH solution possesses the turbostratically disordered structure with high density of defective sites and largely expanded $d$-spacing $\left(d_{002}=0.3384 \mathrm{~nm}\right)$ for attracting and uptaking more $\mathrm{AlCl}_{4}{ }^{-}$ ions with relatively shorter penetration depth. Impressively, the AIB system based on the BEG cathode delivers a high specific capacity of $110 \mathrm{mAh} \mathrm{g}^{-1}\left(4 \mathrm{~A} \mathrm{~g}^{-1}\right)$ and $~ 91 \mathrm{mAh} \mathrm{g}^{-1}$ ( 99.9\% over 10,000 cycles at $\left.10 \mathrm{~A} \mathrm{~g}^{-1}\right)$. Moreover, the BEG cell has high energy and power densities of $247 \mathrm{Wh} \mathrm{kg}^{-1}$ and $44.5 \mathrm{~kW} \mathrm{~kg}^{-1}$. This performance is one of the best among the AIB graphitic carbon materials reported for chloroaluminate anions storage performance. This finding provides great significance for the further development of rechargeable AIBs with high energy, high power density, and exceptionally long life.
\end{abstract}

KEYWORDS Surface modification; Etched graphite; Cathode materials; Energy storage; Aluminum-ion batteries

Gibaek Lee, gibaek@ynu.ac.kr

Advanced Energy Materials Design Lab, School of Chemical Engineering, Yeungnam University, Gyeongsan 38541, Republic of Korea 


\section{Introduction}

Rechargeable aluminum-ion battery (AIB)-based energy storage devices have significant advantages such as low material cost, high abundance, well-defined charge-discharge plateaus, high specific energy, long-term cycle life, and ease of handling in ambient environments [1-3]. Moreover, the safety of metallic aluminum (Al) anodes follows a three-electron-transfer redox reaction owing to its trivalent $\left(\mathrm{Al}^{3+}\right)$ nature (i.e., the strong Coulombic effect of $\mathrm{Al}^{3+}$ ions), which leads to a high theoretical gravimetric capacity $\left(\sim 2980 \mathrm{mAh} \mathrm{g}^{-1}\right)$ and approximately fourfold volumetric capacity $\left(\sim 8046 \mathrm{mAh} \mathrm{cm}^{-3}\right)$ compared with those of lithium anodes $\left(\sim 2080 \mathrm{mAh} \mathrm{cm}^{-3}\right)$ [4-6]. In early efforts, different types of cathode materials, such as carbon materials [7-11], metal oxides $\left(\mathrm{V}_{2} \mathrm{O}_{5}, \mathrm{VO}_{2}\right.$, and $\left.\mathrm{TiO}_{2}\right)$ [12, 13], metal sulfides and selenides [14-16], and conducting polymers [17], have been widely applied to rechargeable AIBs. However, their practical applications were substantially limited due to inadequate cathodic performance such as low specific capacity, low charge-discharge voltage plateaus, and shorter cycle life. Recent studies have utilized various types of graphitic carbon materials, including defect-free graphene aerogel [18], porous 3D graphene foam (GNHPG) [19], graphene microflowers [20], natural graphite flakes [21], small graphite nanoflakes [22], zeolite-templated carbon [23], edge-rich graphene paper [24], carbon nanoscrolls [25], graphene nanoplatelets (GNPs) [26, 27], pyrolytic graphite [28], and $3 \mathrm{H} 3 \mathrm{C}$ graphene films [2]. In addition, conjugated polymers [29] and triangular macrocycles [30] have been extensively explored as cathode materials for chloroaluminate anions/ cation storage in AIBs. Among them, graphitic carbon materials are highly promising owing to their favorable discharge capacity due to the reversible capability of chloroaluminate ions (de)intercalation, ultra-fast charging rate capability, and ultra-stable cycling stability using an ionic liquid (IL) as the AIB electrolyte (consisting of 1-ethyl-3-methylimidazolium chloride $([\mathrm{EMIm}] \mathrm{Cl})$ and aluminum chloride $\left(\mathrm{AlCl}_{3}\right)$ in different molar ratios) [5, 31, 32]. However, 3D graphitic foams, dense natural graphite, edge-rich graphene paper, and $3 \mathrm{H} 3 \mathrm{C}$ graphene films have demonstrated less favorable cathodic performance, including low discharge capacity $\left(\sim 60-128 \mathrm{mAh} \mathrm{g}^{-1}\right)$, insufficient cycle life with rapid capacity decay, and low rate capability due to the poor accessibility of $\mathrm{AlCl}_{4}{ }^{-}$intercalation sites and poor ionic-conducting channels [24]. In addition, these materials exhibited high charge voltage plateaus in the range of 2.2-2.44 $\mathrm{V}$ during the charging process, only slightly lower than the battery electrolyte decomposition cutoff voltage at approximately $2.5 \mathrm{~V}$. This led to severe side reactions during the charging process, resulting in inadequate discharge capacity and limited life cycles $[1,5]$. Therefore, to further develop rechargeable AIBs, it is of great interest to explore new structured cathode materials that possess high energy density, exceptional long life cycle stability and lowered the charge/discharge voltage plateau near to or less than that of the electrolyte decomposition voltage.

Recently, the functional surface treatment of graphitic carbon materials (i.e., natural graphite, graphene, graphite felt) has proven to be a viable strategy for forming different pore sizes (including defect sites, large size holes, or more nanovoids) on their surface structures with a high concentration of redox-active sites without increasing their specific surface area [33-37]. Owing to the wide distribution of redoxactive sites throughout the nanovoids of graphitic carbon materials, many more ions/electrons can easily penetrate/ percolate into the entire material with a relatively shorter penetration depth during the charge/discharge process. Consequently, this phenomenon could contribute to an extremely high specific capacity while maintaining a favorable charge voltage plateau at nearly $2-2.2 \mathrm{~V}$ without any severe side reactions during the charging process. For example, $\mathrm{Lu}$ et al. developed plasma-etched graphene nanoribbons on highly porous 3D graphene (GNHPG) foam as a cathode material for AIBs [19]. The battery cell delivered a discharge capacity of $123 \mathrm{mAh} \mathrm{g}^{-1}$ at a rate of $5 \mathrm{~A} \mathrm{~g}^{-1}$ with a high discharge voltage plateau at approximately $2 \mathrm{~V}$, an exceptionally long cycle life of over 10,000 cycles without any capacity decay, and superior rate performance (reversible specific capacity of $111 \mathrm{mAh} \mathrm{g}^{-1}$ even at the highest current rate of $8 \mathrm{~A} \mathrm{~g}^{-1}$ ). This superior electrochemical performance was realized through plasma etching, which induced an abundant amount of nanovoids distributed throughout the 3D graphene. The large volume of the chloroaluminate ions preferentially percolated/intercalated into the entire active material with a relatively shorter penetration depth of the $\mathrm{AlCl}_{4}{ }^{-}$anions, resulting in a low charge voltage plateau at $2.3 \mathrm{~V}$ during the charge process. Nevertheless, this lower charge voltage plateau caused fewer side reactions leading to damaged electrolyte integrity and undesired by-products 
during the charge process, as well as super-stable cycling performance of GNHPG-based electrodes. In 2018, Zhang and co-workers also demonstrated edge-rich graphene paper using a low-temperature chemical vapor deposition (CVD) process [24]. The resultant edge-rich, thin graphene with abundant interconnected channels enhanced the electrolyte permeability and $\mathrm{AlCl}_{4}{ }^{-}$anions/electron diffusion with a large penetration depth, which reflected a relatively high charge voltage plateau $(\sim 2.2$ and $\sim 2.43 \mathrm{~V})$ during the charge process. However, a reversible capacity as high as $128 \mathrm{mAh}$ $\mathrm{g}^{-1}$ was achieved at $2 \mathrm{~A} \mathrm{~g}^{-1}$ with a superior cycling stability over 20,000 cycles at a current density of $8 \mathrm{~A} \mathrm{~g}^{-1}$. However, the observed charge voltage plateaus were relatively higher than the electrolyte decomposition voltage, resulting in an insufficient discharge capacity in the edge-rich, graphenepaper-based cathode for AIBs.

In this study, we developed a facile process to prepare surface-modified graphitic carbon materials, namely acidtreated expanded graphite (AEG) and base-etched graphite (BEG), as cathode materials for ultra-fast charging and rechargeable AIBs. The as-prepared AEG cathode was composed of abundant micro- to nano-sized porous surface structures with an interlayer distance ( $d$-spacing) of $3.371 \AA$ and a range of different chemical environments realized by surface treatment of pristine graphite (PG) via acidic media. The AIB system incorporating AEG exhibited a specific capacity of $88 \mathrm{mAh} \mathrm{g}^{-1}$ at a current density of $4 \mathrm{~A} \mathrm{~g} \mathrm{~g}^{-1}$ over 1000 cycles with charge voltage plateaus ranging from 2.29 to $2.35 \mathrm{~V}$. The specific capacity was $\sim 80 \mathrm{mAh} \mathrm{g}^{-1}$ at an ultra-high current rate of $10 \mathrm{~A} \mathrm{~g}^{-1}$ across 10,000 cycles with a Coulombic efficiency (CE) of approximately $99.1 \%$. The BEG cathode consisted of abundant exposed-edge graphitic sites having different sizes of pores and large size holes or more nanovoids on the surface structure, with an expanded $d$-spacing of $3.384 \AA$. In addition, the oxygen-containing functionalities introduced by surface-treatment methods via $\mathrm{KOH}$ etching facilitated the fast, reversible chloroaluminate anions kinetics. The battery system consisting of a BEG cathode exhibited lowered charge-voltage plateaus from 2.30 to $2.35 \mathrm{~V}$ for 1000 cycles. In addition, BEG shows a specific capacity of $110 \mathrm{mAh} \mathrm{g}^{-1}$ at a high current density of $4 \mathrm{~A} \mathrm{~g}^{-1}$ with a stabilized CE near $99.7 \%$. The battery maintains an exceptionally long life cycle of over 10,000 cycles without any capacity decay, even at an ultra-high charging rate of $10 \mathrm{~A} \mathrm{~g} \mathrm{~g}^{-1}$ and high rate capability. Moreover, BEG also delivered a specific capacity of $98 \mathrm{mAh} \mathrm{g}^{-1}$ with a $\mathrm{CE}$ of $97 \%$ under ultra-fast charging at $10 \mathrm{~A} \mathrm{~g}^{-1}$ (about $30 \mathrm{~s}$ ) and slow discharging at $4 \mathrm{~A} \mathrm{~g}^{-1}$, exhibiting a specific capacity of $100 \mathrm{mAh} \mathrm{g}^{-1}$ at a constant charging rate of $5 \mathrm{~A} \mathrm{~g}^{-1}$ and by varying the discharge rate from 2 to $10 \mathrm{~A} \mathrm{~g}^{-1}$ over 1000 cycles with a CE of $99 \%$.

\section{Experimental Section}

\subsection{Preparation of AEG and BEG}

PG was obtained from commercial graphite (SigmaAldrich, $<20 \mu \mathrm{m})$. For the preparation of AEG, graphite powders $(2 \mathrm{~g})$ were treated with a mixed acidic solution $(80 \mathrm{~mL})$ of sulfuric acid $\left(\mathrm{H}_{2} \mathrm{SO}_{4}, 95 \%\right.$, Duksan) and nitric acid $\left(\mathrm{HNO}_{3}, 64-66 \%\right.$, Duksan) in a 3:1 ratio under stirring for $24 \mathrm{~h}$. The reaction mixture was diluted with deionized (DI) water $(200 \mathrm{~mL})$. The resulting precipitate was filtered under vacuum after dilution with DI water, washed several times with DI water, and then dried at $80^{\circ} \mathrm{C}$ in air overnight. The resulting mixture was finally annealed at $600{ }^{\circ} \mathrm{C}$ for 30 min in a muffle furnace to obtain the AEG specimen. Base (KOH)-etched graphite (BEG) was prepared using a solution of $4 \mathrm{M}$ potassium hydroxide ( $\mathrm{KOH}, 85 \%$, Duksan). In a typical procedure, a mixture of graphite powder $(2 \mathrm{~g})$ and $4 \mathrm{M} \mathrm{KOH}$ solution $(100 \mathrm{~mL})$ was stirred vigorously at room temperature for $2 \mathrm{~h}$. The resulting precipitate was filtered under vacuum and washed several times with DI water, and then the precipitate was completely dried in an oven at $80^{\circ} \mathrm{C}$. The $\mathrm{KOH}$-etched graphite was annealed at $800^{\circ} \mathrm{C}$ for $2 \mathrm{~h}$ (heating rate: $5^{\circ} \mathrm{C} \mathrm{min}^{-1}$ ) under $\mathrm{N}_{2}$ gas for the $\mathrm{KOH}$ activation reaction. The product was then repeatedly washed with DI water to remove the residual $\mathrm{KOH}$. The final product (BEG) was collected by vacuum filtration and dried in a vacuum oven at $80^{\circ} \mathrm{C}$ for $12 \mathrm{~h}$.

\subsection{Material Characterization}

The morphologies of the surface-treated graphite specimens were characterized by field-emission scanning electron microscopy (FE-SEM, S-4800, HITACHI) and transmission electron microscopy (FT-TEM, Tecnai G2 F20 S-TWIN, FEI) to observe the edges of the graphite and lattice directions. Information about the crystallinity, chemical bonding, and chemical structure was obtained via X-ray diffraction (XRD, DIATOME) equipped with a $\mathrm{Cu} \mathrm{K} \alpha \mathrm{X}$-ray source and 
X-ray photoelectron spectroscopy (XPS, K-Alpha, Thermo Scientific) using an $\mathrm{Al} \mathrm{K} \alpha \mathrm{X}$-ray source. In particular, the carbon material was evaluated using a micro-Raman spectrophotometer (XploRA, Horiba) using an $\mathrm{Ar}^{+}$laser (532 nm). To investigate the specific surface area, pore volume, and average pore size of the graphite, nitrogen molecule adsorption and desorption was carried out using a Physisorption Ion Analyzer (BET, 3-flex, Micromeritics Instruments Corp.) at the Core Research Support Center for Natural Products and Medical Materials at Yeungnam University.

\subsection{Electrochemical Measurements}

The cathode slurries were composed of surface-treated graphite (90 wt \%) as the active material and PVDF (10 wt\%) as a binder in $N$-methyl-2-pyrrolidone (NMP) solvent without any conducting material. The slurries were coated on a 16-mm molybdenum substrate as a current collector and dried at $120^{\circ} \mathrm{C}$ for $12 \mathrm{~h}$ in a vacuum oven. The customized Swagelok cells were fabricated in an argon-filled glovebox to prevent oxidation of the ionic liquid electrolyte. The AIB cell was first optimized in a cell operating at $25{ }^{\circ} \mathrm{C}$ using PG, AEG, and BEG cathodes and an ionic liquid electrolyte consisting of a mixture of 1-ethyl-3-methylimidazolium chloride and aluminum chloride $\left(\mathrm{AlCl}_{3} /[\mathrm{EMIm}] \mathrm{Cl}\right)$ with an optimal ratio of 1.5:1. Aluminum foil was used as the anode, and a glass microfiber filter (GF/D, Whatman) was used as the separator. To confirm the reduction/oxidation peaks, cyclic voltammetry (CV) was measured from 0.0 to $2.5 \mathrm{~V}$ (vs. $\mathrm{Al} / \mathrm{Al}^{3+}$ ) at a scan rate of $0.5 \mathrm{mV} \mathrm{s}^{-1}$. The voltage range for the cycle stability and rate capability was $0.0-2.45 \mathrm{~V}$ (vs. $\mathrm{Al} / \mathrm{Al}^{3+}$ ). To measure the resistance of the cells, EIS (ZIVE SP1, IVIUM Technologies) was performed from 0.1 to $10 \mathrm{kHz}$ with an amplitude of $5 \mathrm{mV}$.

\section{Results and Discussion}

\subsection{Morphological Features of AEG and BEG Cathodes}

Surface-treated graphite cathodes were prepared by acidtreating (AEG) and base-etching (BEG) pristine graphite (PG). In AEG, the edge of the graphitic sheets was exfoliated with abundant micron to nano-sized pores during acid treatment, which can act as redox sites for intercalation of chloroaluminate anions during the charging process. A higher volume expansion of AEG occurred (i.e., by more than threefold) compared to PG and BEG, as illustrated in the optical image in Fig. S1. The KOH etching process generates exposed-edge graphitic carbon sites with many large size holes or more nanovoids and defect sites on the surface of the BEG with a significant content of oxygen-containing functional groups, such as hydroxyl groups $(\mathrm{C}-\mathrm{OH})$, carbonyl/carboxyl groups $(\mathrm{C}=\mathrm{O} / \mathrm{HO}-\mathrm{C}=\mathrm{O})$, and epoxy groups $(\mathrm{C}-\mathrm{O}-\mathrm{C})$, which exist between the BEG layers and at the edges and defect sites. Therefore, the abundant oxygencontaining functional groups act as accessible intercalation/ redox-active sites for chloroaluminate anions intercalation during the charging process and de-intercalation during the discharge process. Figure 1 displays the FE-SEM image of the PG, AEG, and BEG samples. PG particles displayed typical spherical shapes (potato-shaped graphite) with an average diameter of approximately 10-20 $\mu \mathrm{m}$ (Fig. S2), and their surface has a relatively smooth texture with irregular outer surfaces, as strongly indicated in the side and top views in Fig. 1a, d. Moreover, the smooth surface of PG was confirmed by high-resolution SEM images (Fig. 1g). In contrast, the surface morphology of AEG consists of significantly expanded graphitic layers/sheets with honeycomb-like mesoporous structures in the side view in comparison with the PG and BEG samples (Fig. 1b, e), which can be clearly seen in the high-resolution SEM images (Fig. 1h). The side view of AEG reveals widely expanded graphitic layers, yet some layers are attached, and the surface of the AEG is similar to that of PG. The BEG layers contain abundant exposed-edge graphitic carbon sites and expanded graphitic layers, as revealed in the side view of the SEM image in Fig. 1c. Moreover, the top view of the BEG exhibits several defect sites with crater morphology (i.e., large size holes or more nanovoids) on the surfaces, which were estimated to be approximately 0.5 to $1 \mu \mathrm{m}$ in diameter and depth size about 1-2 $\mu \mathrm{m}$ (deep holes or deep craters) covered with approximately $8-10$ graphite layers, as indicated by the yellow line in Fig. $1 \mathrm{i}$ and Fig. S3. These results indicate that many nanosized pores are produced during the $\mathrm{KOH}$ treatment process. These pores are enlarged and become large size holes or more nanovoids with subsequent heat treatment at $800^{\circ} \mathrm{C}$, as obviously evidenced by the SEM images (Figs. 1i and S3). These phenomena were also observed in our previous work [37] and earlier reports by Cheng et al. [35] and Shim et al. [36] Consequently, these characteristics are more beneficial 

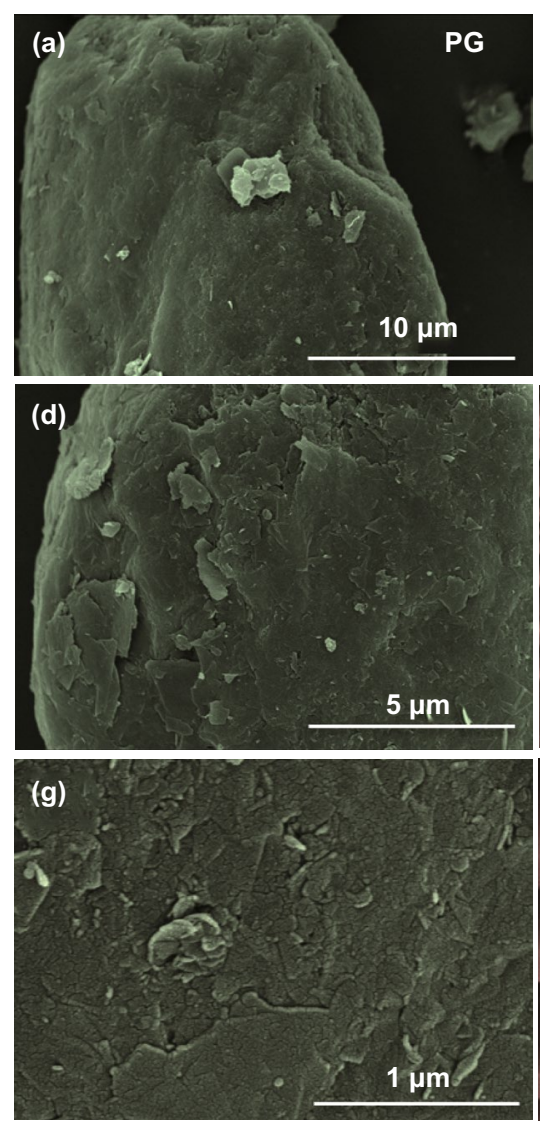
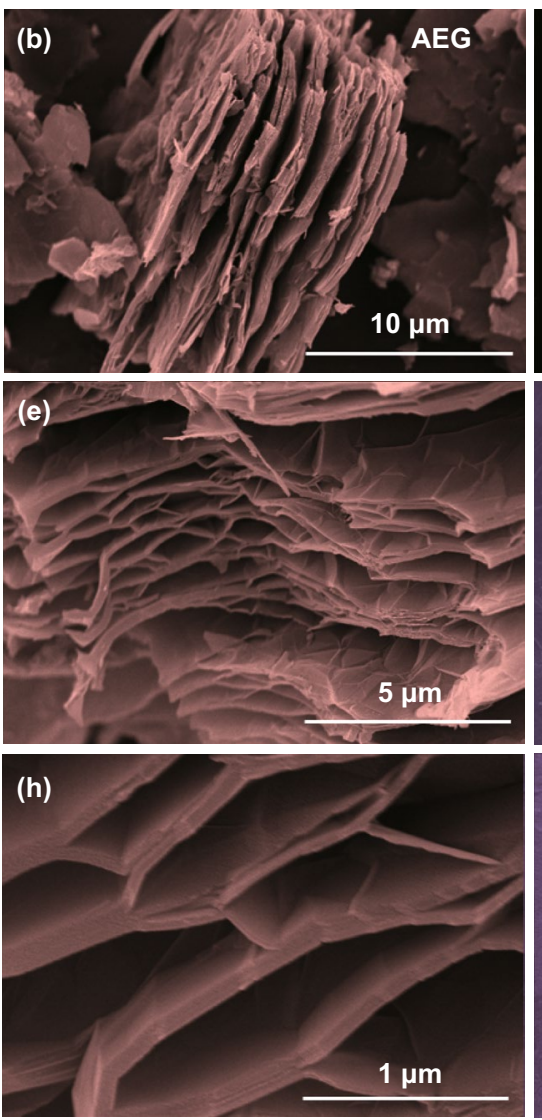
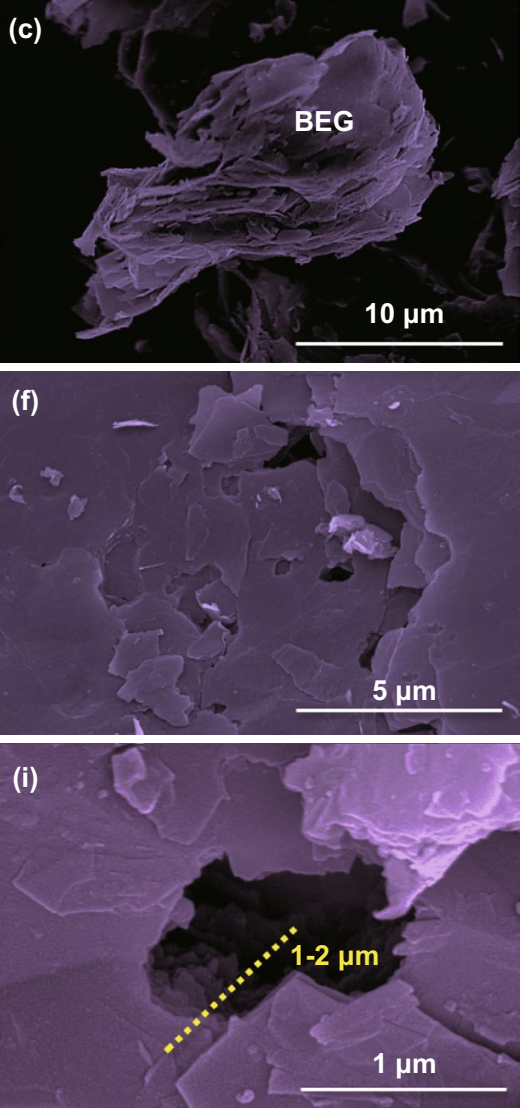

Fig. 1 SEM images of PG, AEG, and BEG; a-c low resolution and $\mathbf{d}-\mathbf{i}$ high-resolution images of samples in different magnification

for facilitating the preferential (de)-intercalation of chloroaluminate anions into the large size holes or more nanovoids and at the edge defect sites of BEG during charge/discharge cycling. This result is further supported by the pore size distribution obtained using the Barrett-Joyner-Halenda (BJH) method (Fig. 3c) and an earlier report by Shim et al. [36].

Figure 2 illustrates TEM images of the three graphite samples. As shown in Fig. 2a, PG did not have graphitic layers at the edge, implying that the graphitic layers overlapped and aggregated. In comparison with PG, the AEG and BEG have clearly separated graphene layers/sheets at the edge of the graphite (Fig. 2b, c). Specifically, the edge of the AEG contains many graphite layers compared to that of BEG. In contrast, many large size holes with sizes of $\sim 500 \mathrm{~nm}$ were formed, and defect nanovoids were distinctly observed on the surface of the BEG, as further evidenced in the TEM images (Fig. S4). Figure $2 \mathrm{~d}-\mathrm{f}$ illustrates the high-resolution TEM (HR-TEM) images of the PG, AEG, and BEG samples with lattice fringes of the corresponding graphites. As illustrated in Fig. 2d, PG is composed of well-defined graphite lattice layers/sheets with long-range-ordered stacking approximately parallel to each other, producing well-organized turbostratic structures. The graphitic lattice directions were further elucidated by the selected area electron diffraction (SAED) pattern (Fig. $2 \mathrm{~g}-\mathrm{i}$ ). The PG shows two lattice directions at the (002) and (004) graphitic peaks, corresponding to interplanar spacing distances ( $d$-spacing) of 0.362 and $0.250 \mathrm{~nm}$, respectively. Figure 2e shows that the AEG sheets also display numerous turbostratically ordered structures with two lattice fringes (as indicated by yellow lines), indexed as the (002) and (004) planes of the graphitic sheets with $d$-spacing of 0.360 and $0.299 \mathrm{~nm}$, respectively. The HR-TEM images of the sample are being formed by phase contrast, so the $d$-spacing could be larger than that calculated from diffraction pattern. Therefore, the $d$-spacing calculated from XRD $(0.3371 \mathrm{~nm})$ and TEM $(0.360 \mathrm{~nm})$ has some difference. The BEG shows 

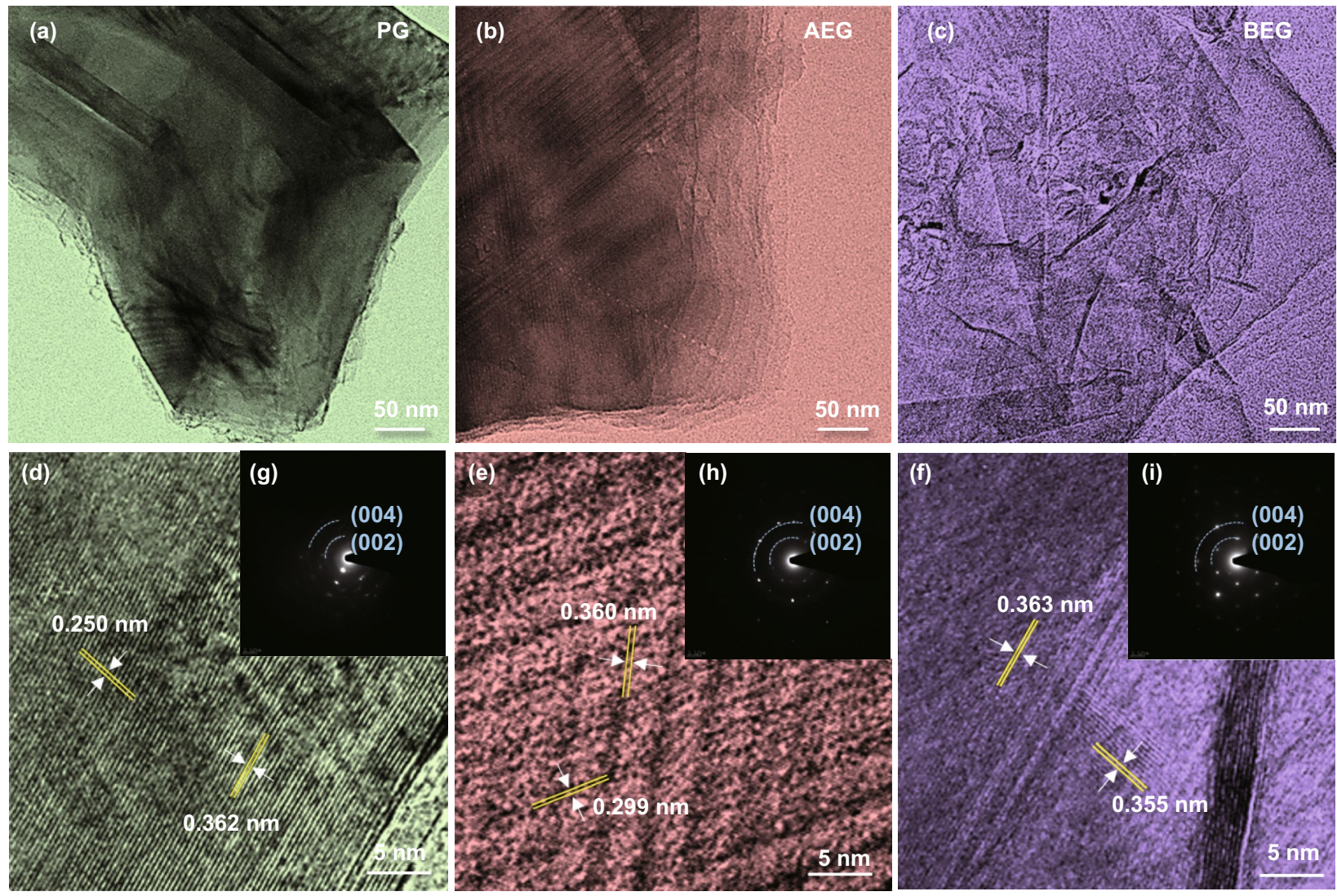

Fig. 2 a-c FE-TEM images and d-f HRTEM images of PG, AEG, and BEG. $\mathbf{g}-\mathbf{i}$ SAED patterns of the corresponding samples

many turbostratically disordered structures with two lattice directions at the (002) and (004) graphitic planes (Fig. 2f), which are associated with $d$-spacing of 0.363 and $0.355 \mathrm{~nm}$, respectively. These results suggest that BEG prepared by $\mathrm{KOH}$ solution gave rise to turbostratic disordered graphitic structures (irregular surface distortion) with an expansion of the $d$-spacing of $\sim 0.003$ (002) and $\sim 0.057 \mathrm{~nm}(004)$ in comparison with that of AEG. Consequently, as illustrated from SEM images (Figs. 1i and S3) and TEM images (Figs. 2c, f and S4) of BEG cathode, the number of graphene layers was fewer and the presence of irregular surface distortion (large size holes or more nanovoids) as compared to AEG. Hence, the presence of high density of defective sites (large size holes or nanovoids) including a significant content of redox active sites (oxygen-containing functional groups) on the surface of BEG cathode can attract and adapt more $\mathrm{AlCl}_{4}{ }^{-}$ions with relatively shorter penetration depth during the charge/ discharge process. Therefore, the rapid intercalation of $\mathrm{AlCl}_{4}{ }^{-}$ions and successive transfer of more $\mathrm{AlCl}_{4}{ }^{-}$ions on the entire surface structure as well as fewer $\mathrm{AlCl}_{4}{ }^{-}$ions intercalation into the space of BEG layer has contributed to provide high BEG cathodic capacity [19].

\subsection{Characterization of AEG and BEG Cathodes}

Figure 3 illustrates the crystallinity, specific surface area, nature of the chemical bonds, and chemical composition of PG, AEG, and BEG samples. The XRD spectrum of PG exhibits a sharp diffraction peak at $2 \theta=26.39^{\circ}$ with a $d$-spacing of $3.374 \AA$, and the other two reflection peaks at $2 \theta=44.4^{\circ}$ and $54.5^{\circ}$ correspond to the (002), (101), and (004) planes of graphite, respectively (JCPDS No. 00-0080415) $[38,39]$. As shown in Fig. 3a, the diffraction peaks diminished after surface treatment with acidic and basic media. AEG shows a decrease in the diffraction peak of the (002) plane, which is almost fivefold lower than that of PG. In addition, the intensities of the reflection peaks for the (100), (101), (103), and (110) planes also 

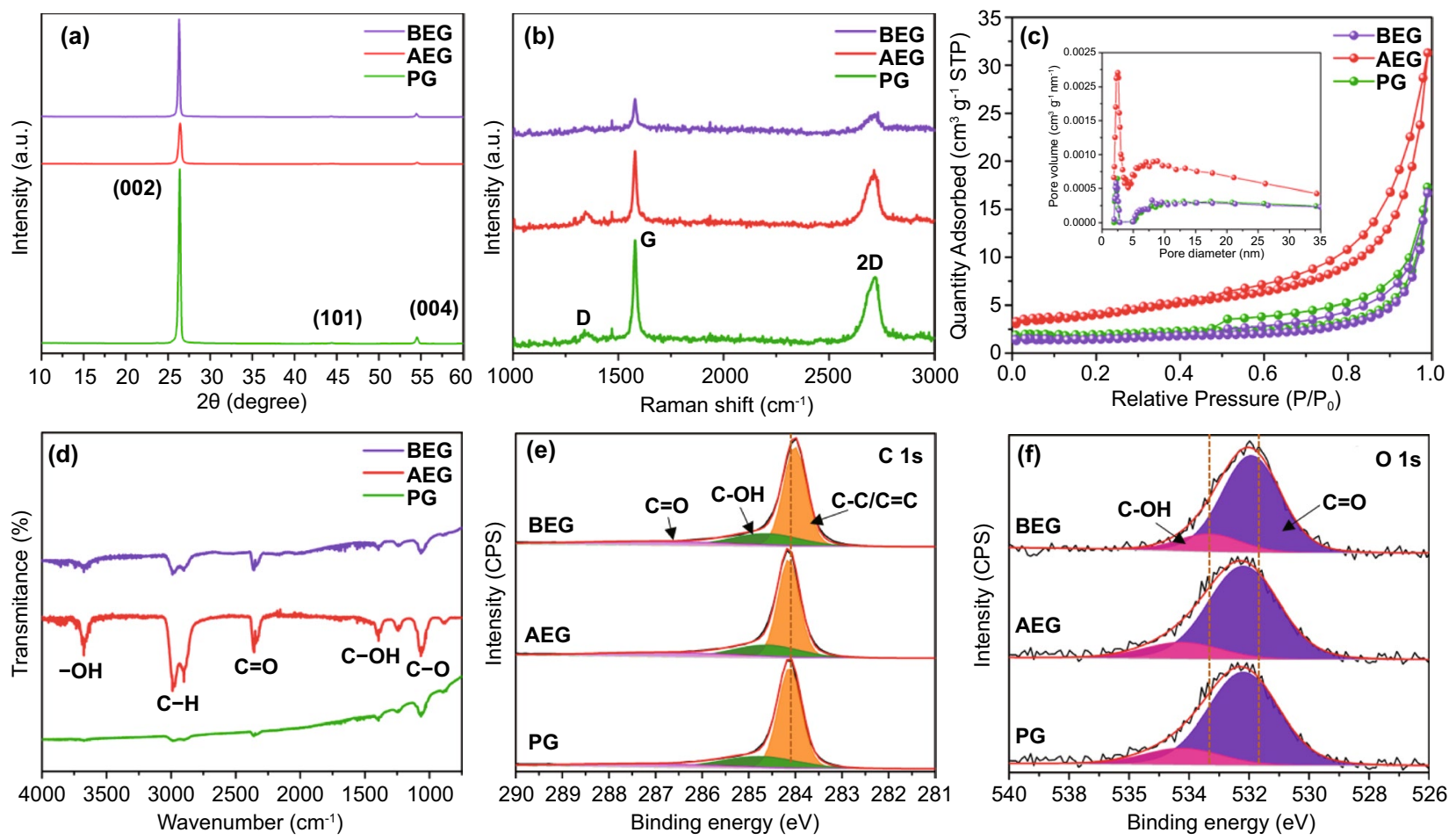

Fig. 3 a XRD pattern, b Raman spectra, c BET isotherm curves (inset; BJH pore size distribution), and d FTIR spectra for PG, AEG, and BEG samples. The XPS profiles of e C $1 \mathrm{~s}$ signal and $\mathbf{f} \mathrm{O} 1 \mathrm{~s}$ signal for PG, AEG, and BEG samples

diminished after acid treatment, as seen in the XRD spectra (Fig. S5a), demonstrating that the surface treatment by the acidic solution caused the low crystallinity of the graphite particles in the AEG samples. The $d$-spacing was calculated using Bragg's equation $(n \lambda=2 d \sin \theta)$ for surface-modified graphite [40]. In AEG, the peak of the (002) plane is shifted to higher angles and located at $2 \theta=26.42^{\circ}$, corresponding to a $d$-spacing of $0.3371 \mathrm{~nm}$ (Fig. S5b) and implying a narrowing/shrinkage in the $d$-spacing of the AEG bulk interlayers in comparison with PG $(0.3374 \mathrm{~nm})$. Such a shrinkage in the $d$-spacing of the AEG layers suggested the oxidation of the intercalated/interlayer groups by acid treatment, followed by the evaporation of intercalated groups as gaseous products such as $\mathrm{CO}_{2}$ and $\mathrm{SO}_{2}$ during the thermal exfoliation process at a low temperature of $600{ }^{\circ} \mathrm{C}$. This process leads to a decrease in the $d$-spacing of AEG and a reduction in the bulk density of PG during acid treatment. In addition, volume expansion occurs with the formation of honeycomb-like microstructures, in which the open and semi-open inner pores range in size from the microscale to nanoscale (SEM images in Fig. 1b, e, h). By contrast, the diffraction peak of the (002) plane for BEG shifted to lower angles, at a position of $2 \theta=26.31^{\circ}$ with a $d$-spacing of $0.3384 \mathrm{~nm}$, indicating an expansion in the $d$-spacing in comparison with that of PG and AEG. Such an enlarged $d$-spacing in BEG could be feasible for accelerating the reversible chloroaluminate anions intercalation kinetics. In other words, the diffusion and migration of $\mathrm{AlCl}_{4}{ }^{-}$and $\mathrm{Al}_{2} \mathrm{Cl}_{7}{ }^{-}$ions would become faster through a shorter penetration depth during cycles in AIBs. In addition, the calculated degree of graphitization (DG), using the equation provided in the supporting information, for BEG is much lower $(65.11 \%)$ than that of both AEG (80.23\%) and PG (76.74\%), indicating that BEG has the turbostratic disorder structure with largely expanded $d$-spacing ( $\left.d_{002}=0.3384 \mathrm{~nm}\right)$ as compared to more turbostratic ordered structures of AEG $\left(d_{002}=0.3371 \mathrm{~nm}\right)$ and PG $\left(d_{002}=0.3374 \mathrm{~nm}\right)$. This feature was further well supported from HR-TEM images (Fig. 2). Therefore, BEG cathode with the turbostratically disordered structure (i.e., decreased the degree of graphitization) can be profound effect on the greater capacitive behavior, implying the intercalation of more $\mathrm{AlCl}_{4}{ }^{-}$ions via the micropores, large size holes or nanovoids to improve more favorable BEG 
cathodic capacity comparing with AEG and PG. The crystal size $L$ of each particle can be calculated by the Scherrer equation $\left(L=\frac{K \lambda}{\beta \cos \theta}\right)$, where $K$ is the constant value of shape factor (0.9-1.84), $\lambda$ is the $\mathrm{X}$-ray wavelength, $\beta$ is the line broadening at half the maximum intensity (FWHM), and $\theta$ is the diffraction angle [41]. In AEG, the sizes of the crystallites comprising the (002) and (004) planes are 21.52 and $20.05 \mathrm{~nm}$, respectively, which are smaller than those of PG (28.24 and $25.23 \mathrm{~nm}$ ). It can be seen that the small crystallites of AEG $\left(L_{c}=21.52 \mathrm{~nm}\right)$ lead to improved electrochemical performance compared to the large crystallites of PG $\left(L_{c}=28.24 \mathrm{~nm}\right)$ [42]. However, the crystallite sizes of BEG $\left(L_{\mathrm{c}}=34.74\right.$ and $\left.28.52 \mathrm{~nm}\right)$ are much larger than those of PG and AEG. Large crystallite sizes indicate a high chloroaluminate anions intercalation capacity due to the high content of redox-active sites accessible in the large size holes or nanovoids for the electrochemical reactions. Some researchers have demonstrated that large crystallites tend to align and orient more easily than smaller crystallites, leading to higher crystallite orientation [43].

Figure $3 \mathrm{~b}$ displays the Raman spectra of the three specimens; the PG spectrum contains three graphite peaks located at 1350,1580 , and $2715 \mathrm{~cm}^{-1}$. The $\mathrm{D}$ band located at $1350 \mathrm{~cm}^{-1}$ is associated with typical lattice defects at the edge of the graphitic layers. Consequently, epoxide groups are covalently bonded to the basal plane of graphite. The $\mathrm{G}$ band at $1580 \mathrm{~cm}^{-1}$ is related to the graphitic carbon structure, which implies that the $\mathrm{C}-\mathrm{C}$ vibration mode of the $s p^{2}$ hybrid bond is present on the surface of graphite [44]. The $I_{D} / I_{G}$ ratios for $P G, A E G$, and $B E G$ were calculated to be $0.086,0.142$, and 0.097 , respectively. The high $\mathrm{I}_{\mathrm{D}} / \mathrm{I}_{\mathrm{G}}$ value indicates the existence of a highly concentrated graphitic defect in the graphite sheets. As a result, AEG shows significantly higher $\mathrm{I}_{\mathrm{D}} / \mathrm{I}_{\mathrm{G}}$ values with respect to those of $\mathrm{PG}$ and $\mathrm{BEG}$, indicating that the oxidation and thermal exfoliation process of PG introduces a high content of oxygen-containing functional groups. Such a process may cause a partial disorder with a large graphitic defect at the carbon edges of AEG [45, 46]. Raman spectrum of PG, AEG, and BEG shows very small peaks between $\mathrm{D}$ and $\mathrm{G}$ bands, which is ascribed to the defectinduced peak, indicating that PG contains defects around the edges of graphitic layers and it may result from the surface dislocations, corrugation, and carbon vacancies.
Therefore, these defect sites may be suitable for promising electrochemical redox properties. In addition, the $2 \mathrm{D}$ band located at $2715 \mathrm{~cm}^{-1}$ is attributed to the second-order Raman scattering of zone-boundary phonons originating from a two-phonon double resonance, which is closely linked to the electronic band structure of graphite [44].

Figure $3 \mathrm{c}$ shows the Brunauer-Emmett-Teller (BET) isotherm, which provides the pore size distribution and specific surface area of the graphite particles. The shape of the nitrogen adsorption/desorption isotherm indicates the type of pore structure. The BET isotherms of the three specimens presented type $\mathrm{H} 2$ hysteresis, which corresponds to slitshaped pores with non-uniform sizes, according to IUPAC [47]. Type $\mathrm{H} 2$ hysteresis exhibits a hysteresis loop range of $\mathrm{P} / \mathrm{P}_{0}$ pressure from 0.5 to 1 . The Barrett-Joyner-Halenda (BJH) shows the pore size distribution of the three specimens (inset in Fig. 3c). The pore sizes of PG and BEG exhibited large with widely distributed in the range of 2-10 nm, respectively. AEG also has a smaller pore size in the range of $2-5 \mathrm{~nm}$, but a higher pore volume with respect to those of PG and BEG. The BET specific surface area of PG, AEG, and BEG was determined to be $7.85,14.08$ and $5.78 \mathrm{~m}^{2} \mathrm{~g}^{-1}$, respectively. Consequently, BEG has the turbostratic disorder structure with more exposed-edge graphitic carbon vacancies, fewer micropores, and large size holes or more nanovoids on the surface (defined as the highdensity defective sites). This result is further well supported by BHJ test results (inset images of Fig. 3c), in which BEG showed the larger pore size diameter in the range of 2-10 nm with reduced specific surface area (BET: ca. $5.78 \mathrm{~m}^{2} \mathrm{~g}^{-1}$ ). This is probably due to the existence of large size high-density defective sites on the surface of BEG as compared to more turbostratically ordered structure of AEG (higher BET surface area: ca. $14.08 \mathrm{~m}^{2} \mathrm{~g}^{-1}$ and smaller pore size diameter: ca. $2-5 \mathrm{~nm}$ ). Earlier reports have also demonstrated that the abundant holes and defect active sites of graphite plane generated by the $\mathrm{KOH}$ etching can provide sufficient cross-plane channels for efficient ionic diffusion, even in a highly compressed form with a low surface area. Therefore, the observed large size holes or nanovoids and defect active sites in BEG could act as excellent host sites with the electrochemical reactions, realizing the facile movement of guest chloroaluminate anions [36, 37].

The nature of the chemical bonds of the three graphite specimens was investigated by Fourier transform infrared 
(FTIR) spectroscopy, and the results are shown in Fig. 3d. The FTIR peaks appearing at 3600, 3000 (doublet peaks), 2350, 1390, and $1060 \mathrm{~cm}^{-1}$ correspond to $-\mathrm{OH}, \mathrm{C}-\mathrm{H}, \mathrm{C}=\mathrm{O}$, $\mathrm{C}-\mathrm{OH}$, and $\mathrm{C}-\mathrm{O}$, respectively $[48,49]$. The FTIR peaks of the AEG are more intense than those of PG and BEG, implying that the AEG has more oxygen-containing functional groups at the graphite plane or at the edge induced by the oxidizing agent. The $s p^{2}$ carbon of graphite is broken by the oxidizing agent, resulting in a change in the $s p^{3}$ bonds connected with many functional groups [50]. Therefore, $\mathrm{AlCl}_{4}{ }^{-}$and $\mathrm{Al}_{2} \mathrm{Cl}_{7}{ }^{-}$ions can react more easily with the oxygen-containing functional groups in the surface structures of AEG and BEG. The XRD and HR-TEM results reveal that the shrinkage/expansion in the $d$-spacing of the AEG and BEG samples is directly correlated to the nature and content of different carbon- and oxygen-containing functional groups in their interlayer and at the edge/defect voids. Hence, the chemical composition of carbon and the content of oxygen-containing functionalities in the graphite materials were predominantly investigated using XPS, and the typical high-resolution XPS profiles of PG, AEG, and BEG are shown in Fig. 3e, f. The C 1 s signal of three different chemically shifted components for three specimens, which could be deconvoluted into two dominant peaks at approximately 284.2 and $285 \mathrm{eV}$, is attributed to $\mathrm{C}-\mathrm{C} / \mathrm{C}=\mathrm{C}$ bonds and $\mathrm{C}-\mathrm{OH}$ bonds, respectively. A small, additional peak is located at $286.5 \mathrm{eV}$ for the three specimens, which is assigned to the carbonyl groups (i.e., $\mathrm{C}=\mathrm{O}$ bonds) [51]. The $\mathrm{O} 1 \mathrm{~s}$ signal for the three specimens is resolved into two dominant peaks centered at 531.5 and $533 \mathrm{eV}$, arising from $\mathrm{C}-\mathrm{OH}$ and $\mathrm{C}=\mathrm{O}$ bonds [52]. Consequently, the XPS profiles of the $\mathrm{C} 1 \mathrm{~s}$ and $\mathrm{O} 1 \mathrm{~s}$ signals for BEG show that the lower binding energy is shifted to the right compared to the spectra of PG and AEG (Fig. 3e), indicating that a greater amount of carbon- and oxygen-containing functional groups (especially for $\mathrm{C}-\mathrm{OH} / \mathrm{C}-\mathrm{O}$ groups) were produced during the surface treatment with $\mathrm{KOH}$ solution. The $\mathrm{C}-\mathrm{OH} / \mathrm{C}-\mathrm{O}$ peak for BEG was more shifted to right than that of AEG and PG, while $\mathrm{C}=\mathrm{O}$ groups were almost unchanged. This result indicating the formation of abundant $\mathrm{C}-\mathrm{OH} / \mathrm{C}-\mathrm{O}$ groups during $\mathrm{KOH}$-treatment. The atomic percentages of carbon- and oxygen-containing functionalities were calculated as $97.78 \%$ and $2.22 \%$ for PG, $98.07 \%$ and $1.93 \%$ for AEG, and $97.93 \%$ and $2.07 \%$ for BEG, respectively (see XPS survey spectra in Fig. S6). It can be seen that the content of oxygen functional groups in BEG $(2.07 \%)$ is lower than that of PG $(2.22 \%)$, demonstrating the reduced the surface oxygen-containing groups by dissociation in the form of $\mathrm{C}-\mathrm{O} / \mathrm{C}-\mathrm{OH}$ groups and $\mathrm{K}$ during $\mathrm{KOH}$-treatment and annealed at $800{ }^{\circ} \mathrm{C}$ [37]. This process generates carbon vacancies on the graphite basal plane, leading to form high-density defective sites and nanopores, large size holes, or nanovoids, as illustrated in Fig. 1f, i.

\subsection{Electrochemical Performance of AEG and BEG Cathodes in AIBs}

$\mathrm{CV}$ curves were measured for each sample in the potential range of 0.0 to $2.5 \mathrm{~V}$ ( $\mathrm{vs} . \mathrm{Al} / \mathrm{Al}^{3+}$ ) at a scan rate of $0.5 \mathrm{mV} \mathrm{s}^{-1}$ (Fig. 4a-c). It can be seen that AEG and BEG have well-resolved redox peaks compared with that of $\mathrm{PG}$, which includes four oxidation peaks (charging/insertion) during the intercalation process and three reduction peaks (discharging/extraction) during the de-intercalation process. This demonstrates the highly reversible chloroaluminate anions (de)-intercalation kinetics in AEG and BEG [25]. The BEG voltammogram displays four distinct oxidation peaks at $1.9,2,2.18$, and $2.35 \mathrm{~V}$ during the intercalation process (Fig. 4c), which are attributed to the intercalation of $\mathrm{AlCl}_{4}{ }^{-}$ions into the fewer interlayer and the edge of the large size holes or nanovoids (defect sites) of BEG. The corresponding three reduction peaks are found at 1.8, 2 , and $2.19 \mathrm{~V}$, which are associated with the extraction of $\mathrm{AlCl}_{4}{ }^{-}$ions from the fewer BEG interlayer and the edge of the defect sites. As a consequence, the simplified redox reactions of $\mathrm{Al} /$ graphite employing $\mathrm{AlCl}_{3} /[\mathrm{EMIm}] \mathrm{Cl}$ during intercalation(charging)/de-intercalation(discharging) can be explained as follows $[11,22,53]$ :

Cathode: $\mathrm{C}_{n}+n \mathrm{AlCl}_{4}^{-} \leftrightarrow \mathrm{C}_{n}\left[\mathrm{AlCl}_{4}\right]+\mathrm{ne}^{-}$

Anode: $\quad 4 \mathrm{Al}_{2} \mathrm{Cl}_{7}^{-}+3 \mathrm{e}^{-} \leftrightarrow \mathrm{Al}^{3+}+7 \mathrm{AlCl}_{4}^{-}$

where $n$ is the molar ratio of carbon atoms to the intercalated chloroaluminate anions in the cathodes. The balanced $\mathrm{AlCl}_{4}{ }^{-}$and $\mathrm{Al}_{2} \mathrm{Cl}_{7}{ }^{-}$concentrations in the electrolyte allowed for an optimal charging capacity at the cathode. There are abundant $\mathrm{AlCl}_{4}{ }^{-}$ions for charging/intercalation in the cathode (Eq. 1) and a sufficient $\mathrm{Al}_{2} \mathrm{Cl}_{7}{ }^{-}$concentration for discharging/electrodeposition at the anode (Eq. 2). In an $\mathrm{AlCl}_{3} /$ [EMIm]Cl ionic liquid electrolyte, the chloroaluminate anions preferentially move through the electrolyte [1]. In addition, AEG and BEG show higher current intensity in their 

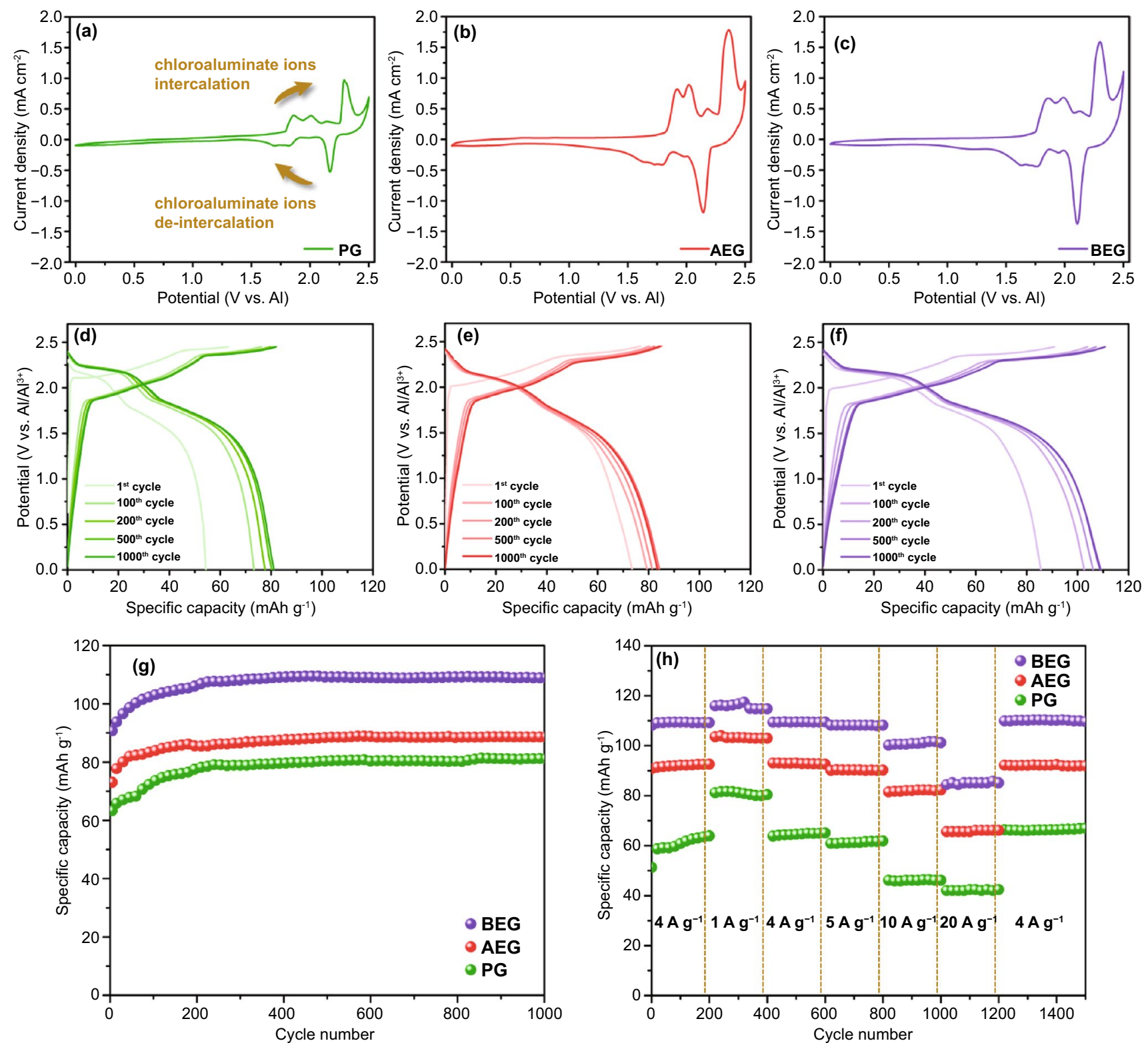

Fig. 4 a-c CV curves and d-f charge-discharge voltage profiles at a current density of $4 \mathrm{~A} \mathrm{~g}^{-1}$ from 1st to 1000th cycles for PG, AEG, and BEG samples. $\mathbf{g}$ Cyclic stability of PG, AEG, and BEG samples at a current rate of $4 \mathrm{~A} \mathrm{~g}^{-1}$ and $\mathbf{h}$ the rate capability of PG, AEG, and BEG samples at various current densities ranging from 1 to $20 \mathrm{~A} \mathrm{~g}^{-1}$

CV curves compared to that of PG, demonstrating a high polarization for electrochemical intercalation of $\mathrm{AlCl}_{4}{ }^{-}$ions into the interlayers, at the edge or defect sites (holes or nanovoids) of AEG and BEG. These results are further supported by the diffusion-controlled processes of AEG and BEG in the electrolyte (Fig. 7). The oxidation peak located over $2.45 \mathrm{~V}$ is due to the electrolyte decomposition or oxidization reaction occurring on the surface of Mo [54].

To investigate the effect of redox-active site distribution on the (de)-intercalation capacity of PG, AEG, and BEG cathodes, the galvanostatic charge-discharge cycling performance in AIB cells was performed at a high current density of $4 \mathrm{~A} \mathrm{~g}^{-1}$, as illustrated in Fig. 4d-f. The optimized cells operating at $25{ }^{\circ} \mathrm{C}$ delivered an initial specific discharging capacity of $54.5 \mathrm{mAh} \mathrm{g}^{-1}$ for PG, $73.6 \mathrm{mAh} \mathrm{g}^{-1}$ for AEG, and $85.7 \mathrm{mAh} \mathrm{g}^{-1}$ for BEG with a CE of approximately $86.3 \%, 95.8 \%$, and $94.3 \%$, respectively. In addition, all three specimens displayed three distinct charge voltage plateaus and two discharge voltage plateaus, as evidenced by their 
differential capacity-voltage (dQ/dV) profiles (Fig. S7). The two major and one minor charge voltage plateaus of the three specimens are found at $\sim 1.8, \sim 2$, and $\sim 2.35 \mathrm{~V}$, and discharge voltage plateaus appeared at $\sim 2.2 \mathrm{~V}$ and $\sim 1.7$, which are in good accordance with the major redox peaks found in the CV curves (Fig. $4 \mathrm{a}-\mathrm{c}$ ). These three charge voltage plateaus are associated with the intercalation of $\mathrm{AlCl}_{4}{ }^{-}$ions into the interlayers and on the surface defect structures of PG, AEG, and BEG. The existence of interlayers, micropores, and surface defect structures would attract more $\mathrm{AlCl}_{4}{ }^{-}$ions and allow to penetrate the large volume of ionic liquids to improve the cathodic capacity. Therefore, this multi-intercalation process provides the capacity rise by existing two major and one minor charge plateaus in the charge curves of PG, AEG, and BEG cathodes (Fig. 4d-f). In addition, it is noteworthy that a significant shift occurred in the discharge voltage plateaus of all three AIB cells based on PG, AEG, and BEG after initial cycles (Fig. 4d-f). In particular, PG displayed a more significant shift to higher voltage plateaus in the subsequent charge-discharge cycling compared to that of AEG and BEG, demonstrating a high polarization in the PG cathode during the insertion/extraction of chloroaluminate anions. Figure $4 \mathrm{~g}$ shows the cycling performance of the PG, AEG, and BEG cathodes at a high current density of 4 A $\mathrm{g}^{-1}$. The specific capacities of PG, AEG, and BEG gradually increased from the 1st to 250th cycles. After cycling over 250 cycles, the specific capacities of PG, AEG, and BEG promptly increased to 82,88 , and $110 \mathrm{mAh} \mathrm{g}^{-1}$, respectively. Impressively, BEG exhibited the highest initial specific capacity of $85.7 \mathrm{mAh} \mathrm{g}^{-1}$ in the first cycle and retained a capacity of $110 \mathrm{mAh} \mathrm{g}^{-1}$ across 1000 cycles in comparison with PG and AEG. To investigate the rate capability, the specific capacities of the three specimens were established by applying a high charging current density from 1 to 20 $\mathrm{A} \mathrm{g}^{-1}$ for 200 consecutive cycles, as shown in Fig. 4h. All three cells were first cycled at a high current density of $4 \mathrm{~A}$ $\mathrm{g}^{-1}$ for 200 cycles to obtain stable cycling states and electrode activation before the rate capability test. As a result, BEG exhibited a discharge capacity of $\sim 116 \mathrm{mAh} \mathrm{g}^{-1}$ at $1 \mathrm{~A} \mathrm{~g}^{-1}, \sim 110 \mathrm{mAh} \mathrm{g}^{-1}$ at $4 \mathrm{~A} \mathrm{~g}^{-1}, \sim 108 \mathrm{mAh} \mathrm{g}^{-1}$ at $5 \mathrm{~A}$ $\mathrm{g}^{-1}$, and $\sim 101 \mathrm{mAh} \mathrm{g}^{-1}$ at $10 \mathrm{~A} \mathrm{~g}^{-1}$. Even at an ultra-high current rate of $20 \mathrm{~A} \mathrm{~g}^{-1}$, BEG delivered the highest specific capacity of $85 \mathrm{mAh} \mathrm{g}^{-1}$, indicating a significantly better chloroaluminate anions intercalation capacity than that of PG $\left(42 \mathrm{mAh} \mathrm{g}^{-1}\right)$ and AEG $\left(66 \mathrm{mAh} \mathrm{g}^{-1}\right)$. When the current density switched rapidly from a high rate $\left(20 \mathrm{~A} \mathrm{~g}^{-1}\right)$ to a low rate $\left(4 \mathrm{~A} \mathrm{~g} \mathrm{~g}^{-1}\right)$, BEG exhibited the highest reversible specific capacity of $\sim 110 \mathrm{mAh} \mathrm{g}^{-1}$ compared to that of PG $\left(66 \mathrm{mAh} \mathrm{g}^{-1}\right)$ and AEG $\left(92 \mathrm{mAh}^{-1}\right)$. These results are mainly attributed to the following high-performance criteria: (i) the enlarged $d$-spacing of BEG and the turbostratically disordered structures with abundant large size holes or more nanovoids on the BEG surface for facilitating high electrolyte permeability and $\mathrm{AlCl}_{4}{ }^{-} / \mathrm{Al}_{2} \mathrm{Cl}_{7}{ }^{-}$ion diffusion dynamics between the ionic electrolyte and cathode; (ii) the continuous electron/charge-conducting matrix/channels in the BEG layers through the distribution of interior active sites, which allows for fast, reversible intercalation/extraction kinetics of the chloroaluminate anions, efficient charge/ current transport, and internal polarization mitigation; and (iii) the existence of the mono-layered graphene-sheet structures with a significant amount of graphitic defects at the carbon edges of BEG $\left(\mathrm{I}_{\mathrm{D}} / \mathrm{I}_{\mathrm{G}}=0.097\right)$ compared to $\mathrm{PG}\left(\mathrm{I}_{\mathrm{D}} /\right.$ $\mathrm{I}_{\mathrm{G}}=0.086$; Fig. $3 \mathrm{~b}$ ), leading to the superior electrochemical performance of BEG in fast-charging AIBs.

\subsection{Cell Performance of BEG Cathodes in AIBs}

The diffusion coefficients of all three cathodes can be explained by the high intercalation capacity of the chloroaluminate anions. The peaks of the $\mathrm{CV}$ curves at different scan rates were used to calculate the diffusion coefficients of the chloroaluminate anions through the Randles-Sevick equation:

$i_{p}=268,600 n^{3 / 2} A D^{1 / 2} C v^{1 / 2}$

where $i_{p}$ is the maximum redox reaction peak current, $n$ is the number of electrons transferred in the redox reaction $(\sim 1), A\left(\mathrm{~cm}^{2}\right)$ is the working electrode area, $D\left(\mathrm{~cm} \mathrm{~s}^{-1}\right)$ is the diffusion coefficient, $C\left(\mathrm{~mol} \mathrm{~cm}{ }^{-3}\right)$ is the concentration of reaction species in $\mathrm{AlCl}_{3} /[\mathrm{EMIm}] \mathrm{Cl}$, and $v\left(\mathrm{~V} \mathrm{~s}^{-1}\right)$ is the scan rate of $\mathrm{CV}$. The diffusion coefficients $\left(D_{o}\right)$ of all redox peaks for PG, AEG, and BEG (Fig. S8), and the overall results are collated in Table $\mathrm{S} 1$. The BEG shows the highest $D_{o}$ values at all redox peaks compared to those of PG and AEG. In particular, BEG exhibits $D_{o} \sim 5.8 \times 10^{-6}$ $\mathrm{cm}^{2} \mathrm{~s}^{-1}$ based on the maximum intensity of the oxidation peak located at $2 \mathrm{~V}$, and $D_{o} \sim 6.82 \times 10^{-6} \mathrm{~cm}^{2} \mathrm{~s}^{-1}$ for the highest intensity of the reduction peak appearing at $2.2 \mathrm{~V}$. In addition, the $\mathrm{AlCl}_{4}^{-}$diffusivities with respect to diffusion rate in PG $\left(5.27 \times 10^{-6} \mathrm{~cm}^{2} \mathrm{~s}^{-1}\right)$, AEG $\left(5.71 \times 10^{-6}\right.$ $\left.\mathrm{cm}^{2} \mathrm{~s}^{-1}\right)$, and BEG $\left(5.80 \times 10^{-6} \mathrm{~cm}^{2} \mathrm{~s}^{-1}\right)$ are found to be approximately 2390 to 2640 times faster or greater than that 
of the bulk graphite and few layer of graphene films (graphitic foam), as summarized and given detailed description about the $\mathrm{AlCl}_{4}{ }^{-}$ion diffusivities in Table S2. These results strongly indicate that the chloroaluminate anions are well diffused throughout the abundant large size holes, or nanovoids at the edges or in the defect sites of the BEG surface and also its wide graphitic interlayers, which results in the superior high-rate electrochemical chloroaluminate anions storage behavior and superior long life cyclic stability of BEG (Fig. 5). The electrochemical surface area (ECSA) plot of the each scan rate and the distances in the current density variation were obtained from the cyclic voltammetry curves (Fig. S9). The slope of the ECSA plot indicates the relatively higher electrochemically active surface area for BEG (0.468) than that of PG (0.448) and AEG (0.433). The plot for BEG also has an enlarged electrochemically active surface area, indicating an achievable high specific capacity. Consequently, BEG delivers an extremely high-rate electrochemical chloroaluminate anions intercalation capacity compared with PG and AEG. Therefore, only BEG has been chosen for further electrochemical tests, such as longterm cyclic stability at different high charging rates, different charge-discharge rate capability tests, AIB performance metrics at ultra-high charging rates, impedance analysis at different redox potentials, determination of capacitive/diffusion ratios, and postmortem analysis of different states of BEG electrodes using different techniques.

The electrochemical cycling stability of BEG was evaluated by charging-discharging at the highest charging rates ranging from 1 to $10 \mathrm{~A} \mathrm{~g}^{-1}$ over 20 consecutive cycles, as shown in Fig. 5a, b. The BEG exhibited a high specific
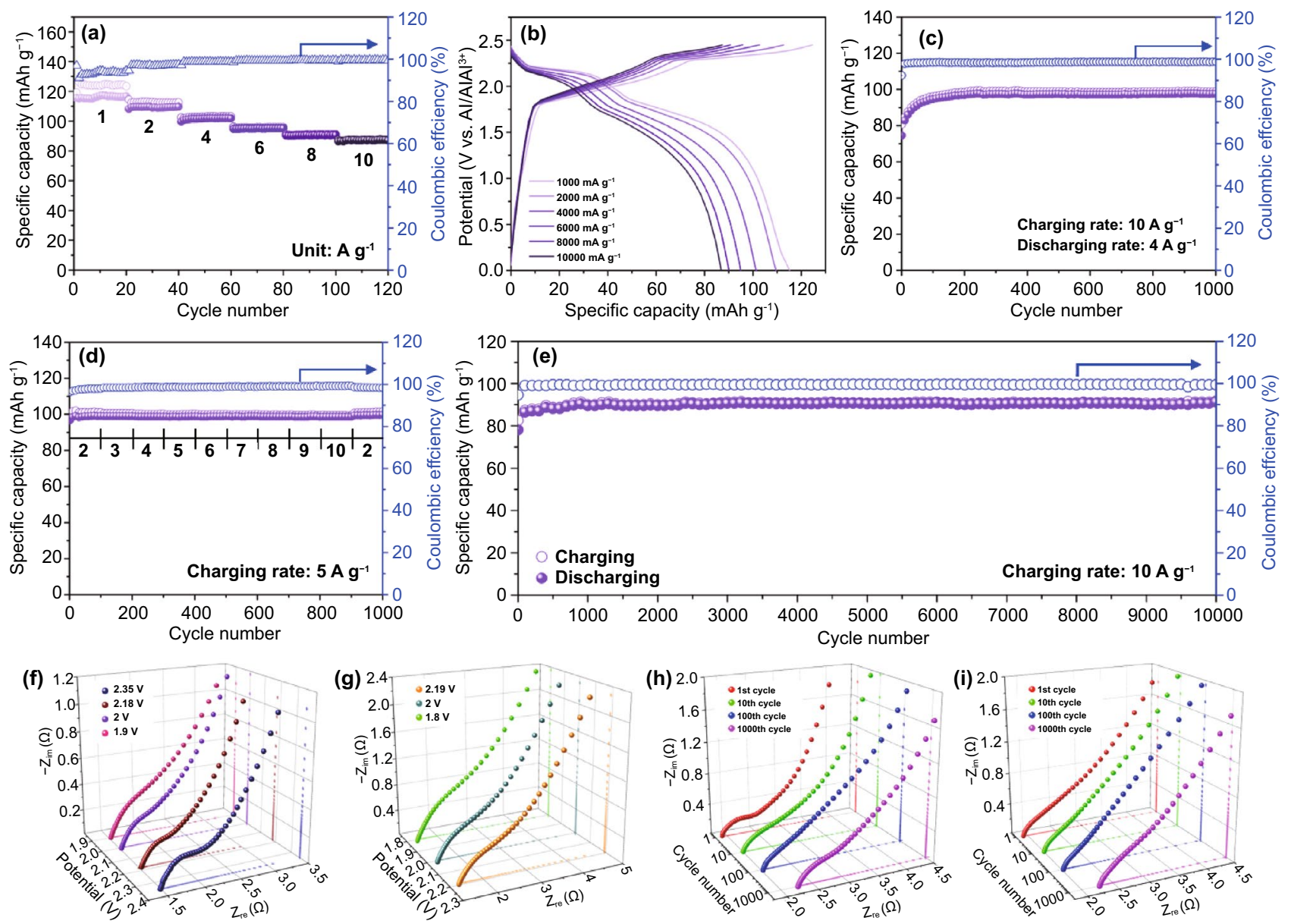

Fig. 5 Electrochemical performance of the BEG cathode. a Rate performance for each current density and b the corresponding charge-discharge voltage profiles of a. c Cyclic stability at the fast charging rate of $10 \mathrm{~A} \mathrm{~g}^{-1}$ and slow discharging rate of $4 \mathrm{~A} \mathrm{~g}^{-1}$ over 1000 cycles, $\mathbf{d}$ Rate capability at a constant charging rate of $5 \mathrm{~A} \mathrm{~g}^{-1}$ with various discharging rates, and e Ultralong-term cyclic stability at a fast current density of $10 \mathrm{~A} \mathrm{~g}^{-1}$ over 10,000 cycles. Nyquist plots for various $\mathbf{f}$ oxidation potentials (intercalation) and $\mathbf{g}$ reduction potentials (de-intercalation) and cycled electrodes at $\mathbf{h}$ an oxidation potential of $2.35 \mathrm{~V}$ and $\mathbf{i}$ Reduction potential of $2.19 \mathrm{~V}$ 
capacity of $116 \mathrm{mAh} \mathrm{g}^{-1}$ during discharging and $124 \mathrm{mAh}$ $\mathrm{g}^{-1}$ during charging at a current density of $1 \mathrm{~A} \mathrm{~g}^{-1}$ (Fig. 5a). At the highest rate of $10 \mathrm{~A} \mathrm{~g}^{-1}$, the specific capacity was maintained at $88 \mathrm{mAh} \mathrm{g}^{-1}$ over 20 cycles with a gradual increase in the CE to $93 \%$ and it eventually stabilized at nearly $100 \%$. It can be seen that the values of the CE in lower of $100 \%$ observed at a current density of 1 and 2 A $\mathrm{g}^{-1}$, which could be attributed to the partly irreversible reactions involved in forming favorable interphases at the cathode and anode of the cell. Furthermore, the presence of excess amount of $\mathrm{Al}$ in the charging process induces the discharging capacity to slightly higher than that of initial capacity. Figure $5 \mathrm{~b}$ displays the corresponding charging-discharging voltage profile, which is consistent with the result obtained in Fig. 4f. It is noteworthy that the chloroaluminate anions (de)-intercalation capacity of BEG decreases with increasing current density, which is attributed to the fact that the ultra-high charging rates can generally be influenced by the BEG cell resistance by insufficient wetting of the electrode [55]. For many practical energy applications like as LIBs, it is strategically quite meaningful for the continuous usage for a long period of time (slow discharge rate) and full charging process in a very short time (fast charge rate) in AIBs because the kinetic difference between fast charging and slow discharging could cause the deterioration or degradation of battery system performance. Therefore, the practical stability of the BEG cathode-based AIB was evaluated by the fast charging process at $10 \mathrm{~A} \mathrm{~g}^{-1}$ (about $30 \mathrm{~s}$ ) and slow discharging process at $4 \mathrm{~A} \mathrm{~g}^{-1}$ over 1000 cycles (Fig. 5c). The process delivers the highest specific charging/discharging capacity of 98.8/97.6 $\mathrm{mAh} \mathrm{g}^{-1}$ across 1000 cycles with a capacity retention of almost $100 \%$ and a CE stabilized to over $99.7 \%$. These features suggest that the slow discharging and fast charging process could be attributed to fast chloroaluminate anions insertion/extraction kinetics in the subsequent cycles owing to wide redox-active site distribution and fewer nanopores, at the edges, and defective sites (large size holes or nanovoids) in BEG. In addition, Fig. 5d illustrates the rate performance of BEG at a constant $5 \mathrm{~A} \mathrm{~g}^{-1}$ charging rate and by varying the discharging rate from 2 to $10 \mathrm{~A} \mathrm{~g}^{-1}$; there is no distinct difference in the specific capacity upon varying the discharging rate. At the initial rate of $2 \mathrm{~A} \mathrm{~g}^{-1}$, the BEG delivered a CE of 98\% and then eventually approached $99.9 \%$ at a high current rate of $10 \mathrm{~A} \mathrm{~g}^{-1}$. This result demonstrates that such a rapid charging rate and variable discharging rate could be applicable in many practical energy storage system, such as public transportation and cell phones. To evaluate the ultra-long-term cycle stability, the AIB cell based on the BEG cathode was subjected to a fast current density of 10 $\mathrm{A} \mathrm{g}^{-1}$ over 10,000 cycles (Fig. 5e). It was revealed that BEG exhibited the longest life cycle (over 10,000 cycles) without any capacity fading as well as fluctuation in comparison with that of PG and AEG (Fig. S10). The BEG cathode delivered the highest specific discharge capacity of $\sim 92 \mathrm{mAh} \mathrm{g}^{-1}$ after 10,000 cycles comparing with AEG $\left(\sim 80 \mathrm{mAh} \mathrm{g}^{-1}\right)$, with an excellent capacity retention of almost $100 \%$. This result indicates the ultra-long-term durability of the AEG and BEG cathodes cycled over 10,000 times (Figs. 5e and S10). As illustrated from SEM images (Figs. 1 and S3) and TEM images (Fig. 2), BEG has a fewer number of graphene layers and the turbostratic disordered structure due to the irregular surface distortion (i.e., high density of defective) with largely expanded $d$-spacing $\left(d_{002}=0.3384 \mathrm{~nm}\right)$, whereas AEG showed more turbostratically ordered structure (less exposed-edge graphitic carbon sites within the graphene structure) covered with abundant micro- to nano-sized pores and expanded $d$-spacing $\left(d_{002}=0.3371 \mathrm{~nm}\right)$. Consequently, the existence of these high density of defective sites (i.e., the exposed-edge graphitic carbon sites and large holes or more nanovoids) on the surface of BEG cathode can attract and adapt more $\mathrm{AlCl}_{4}{ }^{-}$ions with relatively shorter penetration depth during the charge process (more capacitive-controlled process revealed from Fig. S13) compared to AEG cathode. Therefore, the rapid intercalation and successive transfer of more $\mathrm{AlCl}_{4}^{-}$ions on the entire surface and interlayer of BEG have contributed to provide superior charge-storage capacities with a longest life cycles in comparison with AEG cathode. By contrast, PG cathode has $\sim 48 \mathrm{mAh} \mathrm{g}^{-1}$ specific capacity with unstable cycling stability from 3000 cycles to over 10,000 cycles (Fig. S10). This is probably attributed to the deterioration of PG electrode wettability and less long-standing active processes resulting from the potatoshaped structure with homogeneously expanded graphitic layers (i.e., lack of micropores and holes or nanovoids on the surface), and consequently PG showed limit the achievable loads of $\mathrm{AlCl}_{4}{ }_{4}$ ions during the charge process.

The superior electrochemical performance of BEG was investigated via electrochemical impedance spectroscopy (EIS) at different voltages of the chloroaluminate ions insertion/extraction process, as shown in Fig. $5 \mathrm{f}-\mathrm{i}$ and its corresponding supplemented two-dimensional EIS (Figs. S11a 
and b) with equivalent circuit (Fig. S11c), and all impedance components are collated in Table $\mathrm{S} 3$. The $R_{\mathrm{e}}$ is the electrolyte (solution) resistance in the initial region on the real axis, $R_{c t}$ is the charge transfer resistance (or polarization resistance), and $C P E_{\mathrm{dl}}$ is the constant phase element of the double layer capacitance, which is in parallel with the $R_{\mathrm{ct}}$ and Warburg impedance $\left(Z_{\mathrm{w}}\right)$. The diameters of semicircles in the high- and medium-frequency regions indicate the $R_{\mathrm{ct}}$ and the $C P E_{\mathrm{dl}}$. In the low-frequency region, the $Z_{\mathrm{w}}$ is indicative of chloroaluminate ion diffusion within the electrode bulk. It is noticeable from Table $\mathrm{S} 3$ that all redox peaks have an identical $R_{\mathrm{e}}$ of $\sim 1.5 \Omega$, and $R_{\mathrm{ct}}$ assumes lower values for oxidation potentials ( $\mathrm{AlCl}_{4}{ }^{-}$insertion; Fig. 5f) rather than the reduction potentials $\left(\mathrm{AlCl}_{4}{ }^{-}\right.$extraction; Fig. $5 \mathrm{~g}$ ), which indicates the preferential insertion/movement of chloroaluminate anions on the surface of the BEG electrode. Figure $5 \mathrm{~h}$, i shows the Nyquist plots of the 1st, 10th, 100th, and 1000th cycles for the main oxidation potential at $2.35 \mathrm{~V}$ and the reduction potential at $2.19 \mathrm{~V}$. When the number of cycles increased from 1 to 100 , the values of $R_{\mathrm{ct}}$ and $R_{\mathrm{e}}$ were less pronounced than those of the 1000th cycle (Fig. S11a, b). However, the difference in $R_{\mathrm{e}}$ at the 1000th cycle was $\sim 0.27 \Omega$, which is negligible. Therefore, the EIS results for the ultra-long-term cyclic stability of BEG cell over 10,000 cycles indicate no dramatic change of the cell resistance during charge-discharge cycling, demonstrating the superior electrochemical performance of the BEG cathode in AIBs over PG and AEG cathodes.

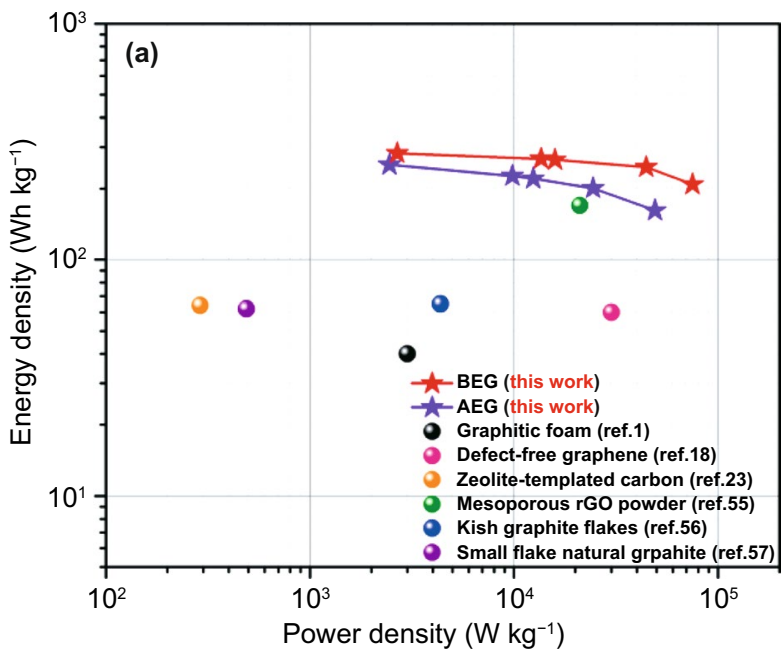

The energy and power density of the battery are expressed by the Ragone plot, as illustrated in Fig. 6. Based on the measured cathode capacity and current densities, the energy density and power density for BEG were calculated as 247 $\mathrm{Wh} \mathrm{kg}^{-1}$ and $44.5 \mathrm{~kW} \mathrm{~kg}^{-1}$ at $10 \mathrm{~A} \mathrm{~g}^{-1}$, respectively. AEG also delivers a high energy density $\left(201 \mathrm{Wh} \mathrm{kg}^{-1}\right)$ and power density $\left(24.4 \mathrm{~kW} \mathrm{~kg}^{-1}\right)$. The summary plots in Fig. 6a show that BEG shows superior AIB performance metrics in terms of energy density compared with those of previously reported state-of-the-art graphitic carbon materials such as graphitic foam [1], defect-free graphene [18], zeolite-templated carbon [23], mesoporous reduced graphene oxide (rGO) powder [56], Kish graphite flakes [57], and smallflake natural graphite [53] (Table S4). Figure 6b shows the Ragone plot of the energy density vs. power density of our $\mathrm{Al} / \mathrm{BEG}$ system, revealing its superior energy storage for AIBs compared to that of commercialized Li-ion batteries, supercapacitors, and electrolytic capacitors. In addition, the $\mathrm{Al} / \mathrm{BEG}$ system shows a higher power density than the full cell.

\subsection{Electrochemical Investigation of the Ion Behavior at BEG Cathodes}

To better understand the excellent electrochemical performance of the BEG electrode, the charge storage mechanism and reaction kinetics were further studied according to

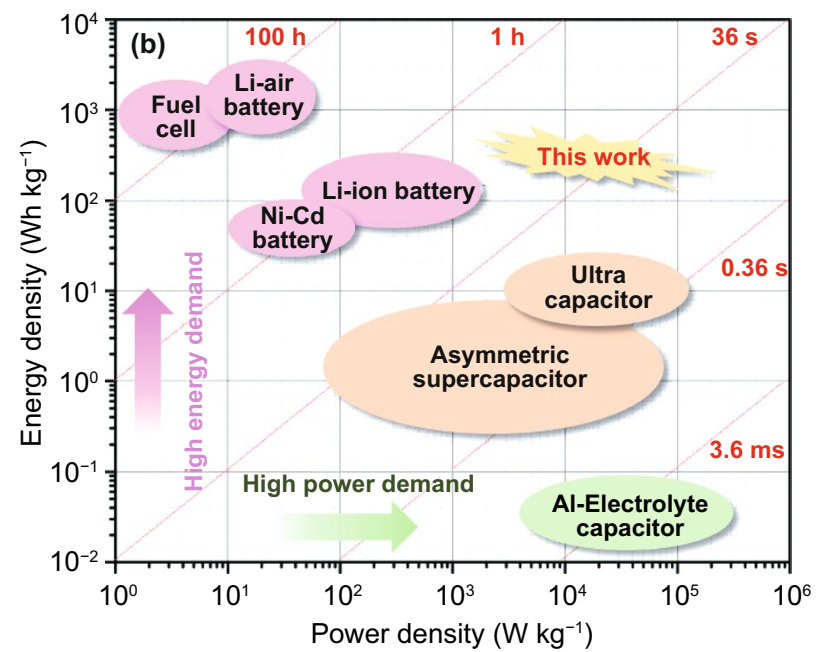

Fig. 6 Ragone plot of energy density vs. power density for AEG and BEG cathodes: comparison with a state-of-the-art graphitic carbon materials reported in the literatures and $\mathbf{b}$ other energy storage systems 
Dunn's method [58, 59], in which CV was used. The electrochemical kinetics of the BEG electrode are governed by diffusion-controlled and capacitive-controlled processes; it is essential to know that which process is dominant. The capacitive effect is characterized by analyzing the CV current at different scan rates, as shown in Fig. 7a. The current response $(i)$ is expressed by the power law:

$i=a v^{b}$

where $i$ is the current, $v$ is the sweep rate, $a$ is a constant, and $b$ is an important indicator of the charge storage kinetics [60]. The type of contribution is indicated by the $b$-value, which determines the slope of the plot of $\log v$ vs. $\log i$ (Fig. 7b). When $b=1$, the dominant charge storage mechanism is a surface-controlled capacitive process at the surface of the electrode. However, $b=0.5$, suggesting that the charge storage is diffusion-controlled [61]. Figure $7 \mathrm{~b}$ shows the $b$-values of BEG at each redox peaks, which are $\sim 1$, except for the peaks located at $\mathrm{O} 1(b=0.512)$ and $\mathrm{R} 1(b=0.714)$, indicating that the charge-discharge process in the BEG electrode has predominantly surface-controlled capacitive characteristics. The current response $(i)$ at a potential $(\mathrm{V})$ can be quantitatively distinguished by a two-part equation accounting for surface capacitive effects $\left(k_{1} v\right)$ and diffusioncontrolled insertion $\left(k_{2} v^{1 / 2}\right)$ :

$i(V)=k_{1} v+k_{2} v^{1 / 2}$

is rearranged to

$i(V) / v^{1 / 2}=k_{1} v^{1 / 2}+k_{2}$

where $v$ is the scan rate. The capacitance percentage can be determined by obtaining the values of $k_{1}$ and $k_{2}$. The relative contribution and the total stored charge associated with both capacitive and $\mathrm{AlCl}_{4}{ }^{-}$ion insertion can be determined [62,
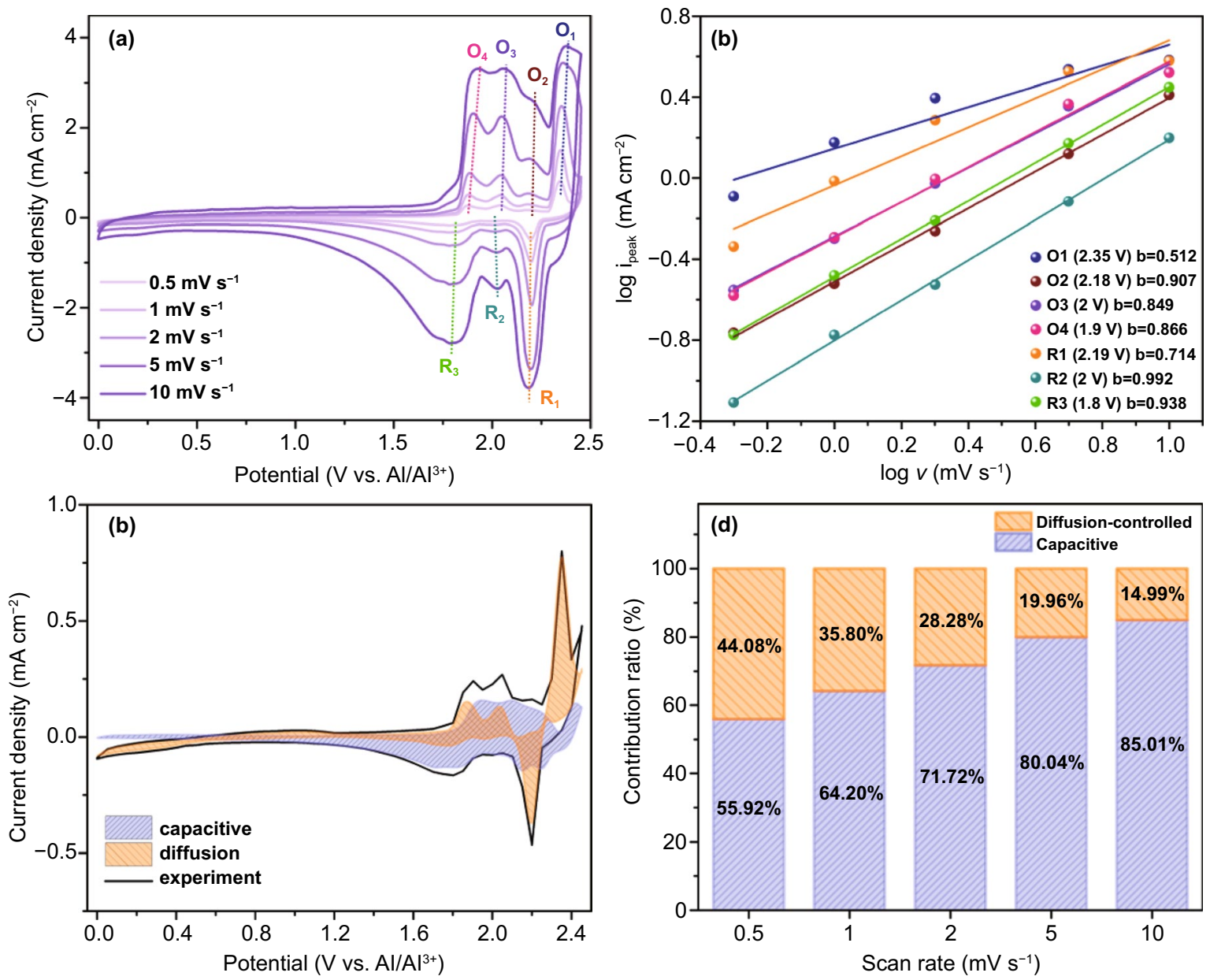

Fig. 7 a CV curves for the BEG cathode at different scan rates, $\mathbf{b} b$-values at different redox voltages, $\mathbf{c}$ contribution ratio of the capacitive- and diffusion-controlled process at a scan rate of $0.5 \mathrm{mV} \mathrm{s}^{-1}$, and $\mathbf{d}$ total capacity contribution ratio for the different scan rates 
63]. The contribution ratio of capacitive effects was estimated at a scan rate of $0.5 \mathrm{mV} \mathrm{s}^{-1}$, as shown in Fig. 7c. The diffusion-controlled reaction region is marked by orange, which accounts for approximately $35.54 \%$ of the total stored charge. The blue region indicates the contribution of capacitive effects, which is approximately $64.46 \%$. With increasing scan rates, the fraction of the capacitive-controlled region (blue) was higher than the diffusion-controlled region (orange), as indicated in the diffusion/capacitive-controlled contribution curves (Fig. S12). The total contribution ratios of the capacitive- and diffusion-controlled processes in the EPG electrode at different scan rates are shown in Fig. 7d. It is noted that the percentage of the capacitive region gradually increases as the scan rate is increased from 0.5 to $10 \mathrm{mV} \mathrm{s}^{-1}$. The ratios of $55.92 \%$ and $85.01 \%$ mainly arose from the capacitive-controlled process at 0.5 and $10 \mathrm{mV} \mathrm{s}^{-1}$, respectively. These results strongly indicate that the superior rate performance of $\mathrm{BEG}$ for AIBs originates from the high contribution ratio of the capacitive-controlled process. This indicates a dominant capacitive behavior during the charge-discharge process of the BEG electrode while maintaining the fast redox reaction kinetics and rate-independent behavior during cycling. With the increase in scan rates, the fraction of the diffusion-controlled process decreased due to insufficient time for the $\mathrm{AlCl}_{4}{ }^{-}$ions to preferentially insert into the interior active sites of the BEG electrode [64]. In addition, the total contribution ratios of the capacitiveand diffusion-controlled processes of PG, AEG, and BEG revealed that the capacitive character (blue region) increased as the scan rate increased, resulting in a linear relationship (Fig. S13). The slope indicates that the surface-modified graphites have greater electrochemical reaction sites for efficient chloroaluminate ions storage. The AEG had the highest slope value of 4.569 compared to PG (4.521) and BEG (3.701), indicating the highest amount of reaction sites. Nevertheless, BEG has a larger capacitive region owing to many large size holes or more nanovoids and defect sites on the surface of the BEG graphitic layers. The possible reason is the fact that the electrochemical quantities (i.e., electron transfer rate, capacitance and density of electronic states) are mainly dependent on the defect density of the basal plane of graphite. As illustrated in SEM images (Figs. 1 and S3) and TEM images (Figs. 2 and S4), BEG comprises the highdensity defective sites on the surface structure with large size holes or more nanovoids as compared to AEG. That is why BEG showed larger pore size diameter in the range of 2-10 nm with significantly reduced estimated surface area (BET: $\sim 5.78 \mathrm{~m}^{2} \mathrm{~g}^{-1}$ ) as compared to those of AEG (higher BET surface area: $~ 14.08 \mathrm{~m}^{2} \mathrm{~g}^{-1}$ and reduced pore size diameter: $2-5 \mathrm{~nm}$ ). As a result, these large size holes or more nanovoids on the surface/defect edge of BEG would attract and adapt more $\mathrm{AlCl}_{4}{ }^{-}$ions through the penetration of large volume of ionic liquids to produce robust pseudocapacitive charge-storage amount compared to with PG and AEG (Fig. S13). Therefore, BEG exhibited a high portion of capacitance effect in the whole capacity in comparison with that of AEG and PG.

To compare the microstructures of the BEG surface before and after charged/discharged cycled electrodes, SEM-energy-dispersive X-ray (SEM-EDX) mapping of the BEG electrodes over 1000 cycles is shown in Fig. 8a-c. Before cycling, the pristine electrode of the BEG microstructure has a smooth surface with a high concentration of carbon and a lower content of $\mathrm{Al}$ and $\mathrm{Cl}$ (Fig. 8a). However, the surfaces of the electrodes have seemingly blurred films after cycling, as evident in the SEM images in Fig. 8b, c, which is mainly attributed to the decomposition of the electrolyte and side reactions occurring during the charging and discharging processes. The SEM-EDX images clearly reveal strong $\mathrm{Al}$ and $\mathrm{Cl}$ element signals uniformly distributed over the entire BEG electrode surface at a charged state of $2.45 \mathrm{~V}$. Furthermore, the distribution of these element signals $(\mathrm{Al}$ and $\mathrm{Cl})$ was markedly weaker in the discharged state $(0.0 \mathrm{~V})$. These results provide strong evidence that $\mathrm{AlCl}_{4}{ }^{-}$is preferentially intercalated into the defective sites (i.e., large size holes or nanovoids) of the BEG graphitic layers during the charging process; this conclusion is supported by the blurrier film surface in the charged state and strong $\mathrm{Al}$ and $\mathrm{Cl}$ signals in Fig. 8b [64]. Moreover, the remaining $\mathrm{Al}$ signals in the fully discharged state are tentatively attributed to the irreversible intercalation of $\mathrm{Al}$ species $\left(\mathrm{AlCl}_{4}{ }^{-}\right.$and $\left.\mathrm{Al}_{2} \mathrm{Cl}_{7}^{-}\right)$into the graphitic layers at the edges or defect sites (Fig. 8c). Weak Cl signals were also observed in the discharged state, which is ascribed to the irreversible side reactions between $s p^{2}$ carbon and $\mathrm{Cl}^{-}$species at high voltages [65]. Ex-situ XPS studies were carried out to reveal the chemical state of the BEG electrodes at charging/ discharging states. Figure $8 d-f$ shows the XPS profiles of C Is, $\mathrm{Al} 2 \mathrm{p}$, and $\mathrm{Cl} 2 \mathrm{p}$ signals for the pristine BEG electrode, BEG electrode fully charged to $2.45 \mathrm{~V}$, and BEG electrode discharged to $0.0 \mathrm{~V}$, respectively. The XPS profile of C Is signals displays two dominant peaks at 284.3 and $286 \mathrm{eV}$ for the pristine, charged, and discharged states of the BEG electrode (Fig. 8d), which correspond to the binding energies of $\mathrm{C}-\mathrm{C} / \mathrm{C}=\mathrm{C}$ bonds and $\mathrm{C}-\mathrm{OH}$ groups, respectively. The small peak appearing at $290 \mathrm{eV}$ can be assigned to the $\mathrm{CF}_{2}$ groups of the PVDF binder in BEG electrode [66]. When the 
(a)
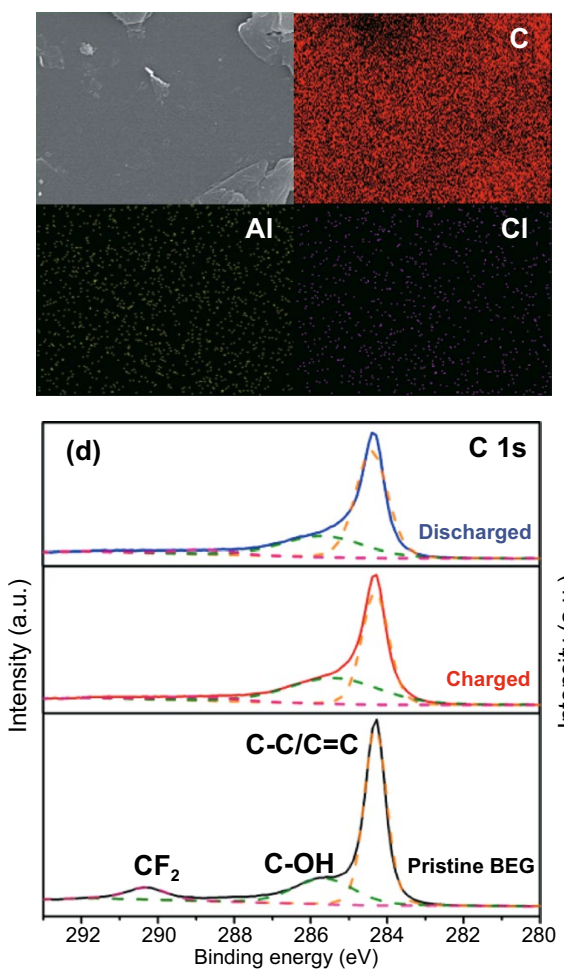

(b)
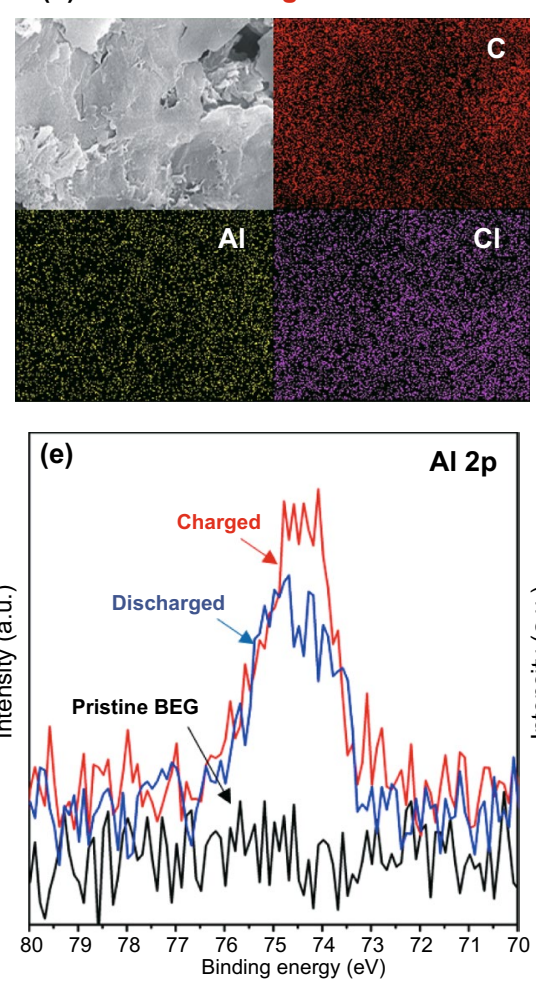

(c)
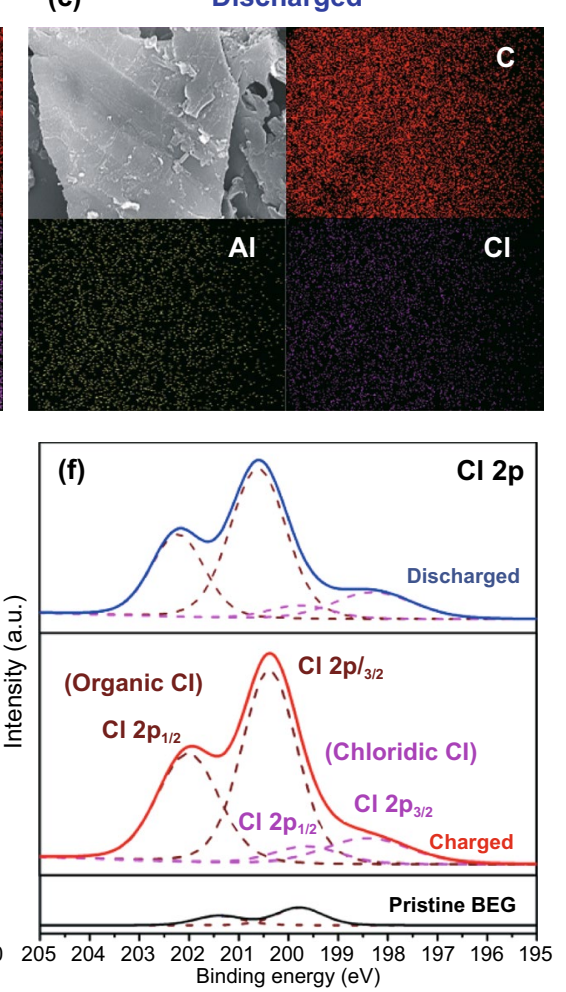
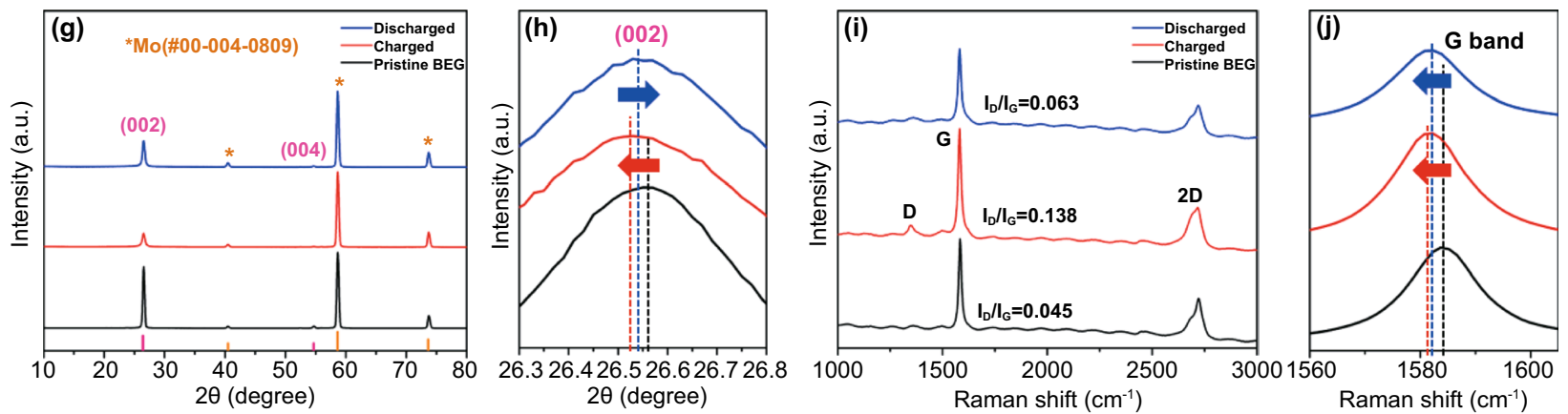

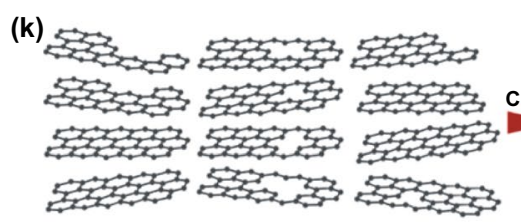

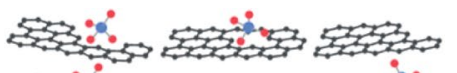

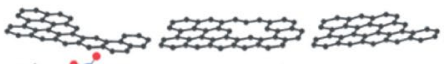

Charged Dischar

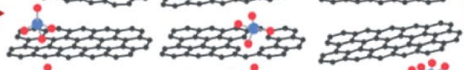

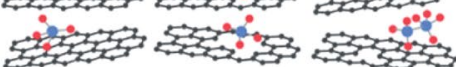

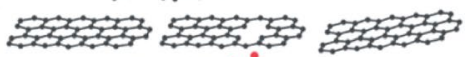

运运

$\because \mathrm{AlCl}_{4}^{-} \quad \because \mathrm{Al}_{2} \mathrm{Cl}_{7}^{-}$

Fig. 8 SEM-EDX analysis of a pristine, $\mathbf{b}$ charged, and $\mathbf{c}$ discharged BEG electrode. The XPS profiles of $\mathbf{d} \mathrm{C}$ Is, e $\mathrm{Al} 2 \mathrm{p}$, and $\mathbf{f} \mathrm{Cl} 2 \mathrm{p}$ signals, $\mathbf{g}$ XRD patterns, $\mathbf{h}$ the enlarged spectrum of (002) plane peaks for different states of BEG electrode. $\mathbf{i}$ Raman spectrum for different states of the pristine, charged, and discharged BEG electrode, and $\mathbf{j}$ the enlarged spectrum of the $\mathrm{G}$ band peaks for comparison. $\mathbf{k}$ Schematic diagram of the transportation of chloroaluminate anions into BEG electrode during charge-discharge cycling

electrodes were fully charged to $2.45 \mathrm{~V}$ and discharged to $0.0 \mathrm{~V}$, the intensities of the dominant $\mathrm{C}-\mathrm{C} / \mathrm{C}=\mathrm{C}$ and $\mathrm{C}-\mathrm{OH}$ peaks are markedly diminished, demonstrating the reduction of redox-active sites and $\mathrm{C}-\mathrm{OH}$ groups as a result of the intercalation of $\mathrm{AlCl}_{4}{ }^{-}$into the multichannel, open defects, holes or nanovoids structure of BEG. Figure $8 \mathrm{e}, \mathrm{f}$ illustrates that the $\mathrm{Al} 2 \mathrm{p}$ peak $(74.5 \mathrm{eV})$ and $\mathrm{Cl} 2 \mathrm{p}$ peak $(200.5 \mathrm{eV})$ become more pronounced in the fully charged state $(2.45 \mathrm{~V})$ 
relative to that of the fully discharged state $(0.0 \mathrm{~V})$. These peaks are relatively weak for the pristine BEG electrode. The XPS profile of the $\mathrm{Cl} 2 p$ signal shows a decrease in the intensity of the organic $\mathrm{Cl} 2 \mathrm{p}_{1 / 2}$ peak $(202.1 \mathrm{eV})$ after discharging to $0.0 \mathrm{~V}$, demonstrating the formation of $\mathrm{C}-\mathrm{Cl}$ bonds as a result of de-intercalation of $\mathrm{AlCl}_{4}{ }^{-}$ions. These results reveal the intercalation of $\mathrm{AlCl}_{4}{ }^{-}$and $\mathrm{Al}_{2} \mathrm{Cl}_{7}{ }^{-}$during the charging process $[67,68]$. Moreover, a substantial reduction of the $\mathrm{Al}$ and $\mathrm{Cl}$ element signals was apparent in the fully discharged state, indicating extraction of $\mathrm{AlCl}_{4}{ }^{-}$ions. Ex situ XRD was also used to monitor the crystal structure changes in the different states of the BEG electrode, as shown in Fig. 8g, h. When the charged state is $2.45 \mathrm{~V}$, the (002) plane peak intensity is decreased compared to that of the pristine BEG. This could be attributed to the intercalation of $\mathrm{AlCl}_{4}{ }^{-}$ions into the large size holes or nanovoids and at the edge/defect sites of the BEG layers during the charging process. As the BEG electrode was fully discharged to $0.0 \mathrm{~V}$, the (002) plane peak increased in intensity compared with the charged state, demonstrating the extraction of $\mathrm{AlCl}_{4}{ }^{-}$ions from the defective sites of BEG layers. In addition, the (002) plane peak is significantly shifted to lower $2 \theta$ values $\left(2 \theta=26.52^{\circ}\right.$, $\left.d_{002} \sim 3.367 \AA\right)$ in the charged state $(2.45 \mathrm{~V})$ with respect to that of the pristine $\left(2 \theta=26.56^{\circ}, d_{002} \sim 3.362 \AA\right)$ and discharged state $\left(2 \theta=26.55^{\circ}, d_{002} \sim 3.363 \AA\right)$. This result strongly suggests that the energy-storage mechanism of BEG involves the incorporation of more $\mathrm{AlCl}_{4}{ }^{-}$ions into the exposed graphitic carbon sites and large size holes or nanovoids of the BEG layers [67]. This intercalation mechanism of $\mathrm{AlCl}_{4}{ }^{-}$was further confirmed by ex situ Raman spectroscopy of the BEG electrodes in the charge and discharge states, as shown in Fig. 8i, j. The Raman spectra exhibited two main peaks at 1350 and $1592 \mathrm{~cm}^{-1}$, corresponding to the $\mathrm{D}$ and $\mathrm{G}$ bands, respectively. These peaks become more intense and shift to lower Raman frequency $\left(1591.5 \mathrm{~cm}^{-1}\right)$ when charged to $2.45 \mathrm{~V}$ relative to those of the discharged state and pristine BEG electrodes. The $\mathrm{I}_{\mathrm{D}} / \mathrm{I}_{\mathrm{G}}$ ratios for the pristine, charged, and discharged states of the BEG electrode were calculated as $0.045,0.138$, and 0.063 , respectively (Fig. 8i). These results strongly indicate that the $\mathrm{AlCl}_{4}{ }^{-}$ions mainly participate in the energy storage capacity during the charging process. The 2D band also became broader with significantly increased intensity at $2.45 \mathrm{~V}$ in comparison with that of the discharged and pristine electrodes. Moreover, the $\mathrm{G}$ band peak for the charged and discharged states is shifted to lower frequencies $\left(1581.7\right.$ and $1581.9 \mathrm{~cm}^{-1}$, respectively) relative to the pristine state $\left(1584.1 \mathrm{~cm}^{-1}\right)$, as indicated by the arrow in Fig. 8 j. Figure $8 \mathrm{k}$ is the schematic diagram of insertion/extraction of $\mathrm{AlCl}_{4}{ }^{-}$into the $\mathrm{BEG}$ graphitic layers. In charging process, chloroaluminate anions ( $\mathrm{AlCl}_{4}{ }^{-}$and $\mathrm{Al}_{2} \mathrm{Cl}_{7}{ }^{-}$ions) insert to the graphitic sheets through large size holes or nanovoids, the edge and defect sites, which can have fast insertion kinetics. Furthermore, when $\mathrm{AlCl}_{4}{ }^{-}$ions extract from the BEG layers (discharging process), which allows for fast, reversible extraction kinetics and efficient charge transport. A comparison table is provided to highlight our results (Table S5), which show that the surface-treated graphite cathodes (AEG and BEG) have superior AIB performance metrics in terms of high specific capacity at ultra-high charging rates; a super-stable, long life of up to 10,000 cycles; and a CE stabilized to nearly $100 \%$ compared to that of previously reported state-of-theart graphitic carbon materials. We also summarized the introduction of different technologies that could generate adequate different surface defects on the graphitic carbon materials and their effect on the (de)intercalation capacities, as shown in Table S6. Among the different methods that process different high density of surface defects, such as vacancy holes and polygons, deep craters, large size defects, 3D mesh network and nanovoids, high volume of pore regularity, and fragmentized particles, our methods of acid- and base-etched treatment (i.e., AEG and BEG) have been shown to exhibit profound effect on the attract and uptake of more $\mathrm{AlCl} 4$ - ions through the penetration of large volume ionic liquids into surface defects rather than only surface/space modified cathodic materials, finally leading to the superior performance of AIBs at an ultra-fast charging current rates. Therefore, this findings revealed that enlarging the graphite $d$-spacing, the generating exposed graphitic carbon sites, large size holes or more nanovoids at the edge/defect sites in the graphitic plane are more beneficial to attain efficient diffusion dynamics and reversible (de)-intercalation kinetics of chloroaluminate anions towards extremely high storage capacity and stable performance in AIBs.

\section{Conclusions}

In summary, we developed ultra-fast charging AIBs using surface-treated graphitic cathode materials with superior performance. The highest specific capacities were achieved about 89 and $110 \mathrm{mAh} \mathrm{g}^{-1}$ at $4 \mathrm{Ag}^{-1}$ for the AEG and BEG 
cathodes, respectively. Both AEG and BEG cathodes showed a super-stable cycling life of 10,000 charge-discharge cycles without any capacity decay even at ultra-high current densities, along with a high discharge voltage plateau near $2.2 \mathrm{~V}$. The Al/BEG cells exhibited an ultra-high rate performance in comparison with that of the $\mathrm{Al} / \mathrm{AEG}$ and $\mathrm{Al} / \mathrm{PG}$ cells owing to the wide distribution of redox-active sites at the edge and over the surface defects (i.e., large size holes or nanovoids) of the BEG cathode introduced by the $\mathrm{KOH}$ etching process. At the same time, the expanded graphitic interlayers were maintained in BEG, which accelerated the diffusion dynamics and efficient (de)-intercalation kinetics of $\mathrm{AlCl}_{4}{ }^{-}$storage even at fast charging current rates. Our fabricated $\mathrm{Al} / \mathrm{AEG}$ and $\mathrm{Al} / \mathrm{BEG}$ battery cells can afford energy densities of $\sim 201$ and $\sim 247 \mathrm{Wh} \mathrm{kg}^{-1}$ at high power densities of up to $\sim 49.1$ and $\sim 75.1 \mathrm{~kW} \mathrm{~kg}^{-1}$, respectively, which are higher than those of lithium-ion batteries, supercapacitors, and electrolytic capacitors, as detailed in the Ragone plot. Therefore, our findings contribute to the development of surface-modified graphitic carbon materials as cost-effective, safe, and fast-charging advanced electrode materials for high-energy-density AIBs.

Acknowledgements This work was supported by the Basic Science Research Program through the National Research Foundation of Korea (NRF), funded by the Ministry of Education (No. NRF2019R1I1A3A01046928) and the "Human Resources Program in Energy Technology" of the Korea Institute of Energy Technology Evaluation and Planning (KETEP), granted financial resource from the Ministry of Trade, Industry \& Energy, Republic of Korea (No. 20204010600100).

Author's Contributions Jisu Kim performed to the investigation, formal analysis, data curation, and writing - original draft. Michael Ruby Raj contributed to the conceptualization, formal analysis, writing - review, and editing. Gibaek Lee contributed to the conceptualization, data curation, supervision, project administration, writing - review, and editing.

Open Access This article is licensed under a Creative Commons Attribution 4.0 International License, which permits use, sharing, adaptation, distribution and reproduction in any medium or format, as long as you give appropriate credit to the original author(s) and the source, provide a link to the Creative Commons licence, and indicate if changes were made. The images or other third party material in this article are included in the article's Creative Commons licence, unless indicated otherwise in a credit line to the material. If material is not included in the article's Creative Commons licence and your intended use is not permitted by statutory regulation or exceeds the permitted use, you will need to obtain permission directly from the copyright holder. To view a copy of this licence, visit http://creativecommons.org/licenses/by/4.0/.

Supplementary Information The online version contains supplementary material available at https://doi.org/10.1007/ s40820-021-00698-0.

\section{References}

1. M.C. Lin, M. Gong, B. Lu, Y. Wu, D.Y. Wang et al., An ultrafast rechargeable aluminium-ion battery. Nature 520, 325-328 (2015). https://doi.org/10.1038/nature14340

2. H. Chen, H. Xu, S. Wang, T. Huang, J. Xi et al., Ultrafast all-climate aluminum-graphene battery with quarter-million cycle life. Sci. Adv. 3, eaao7233 (2017). https://doi.org/10. 1126/sciadv.aao7233

3. Z. Yu, S. Jiao, S. Li, X. Chen, W.L. Song et al., Flexible stable solid-state al-ion batteries. Adv. Funct. Mater. 29, 1806799 (2019). https://doi.org/10.1002/adfm.201806799

4. J. Muldoon, C.B. Bucur, T. Gregory, Quest for nonaqueous multivalent secondary batteries: magnesium and beyond. Chem. Rev. 114(23), 11683-11720 (2014). https://doi.org/ $10.1021 / \mathrm{cr} 500049 \mathrm{y}$

5. H. Sun, W. Wang, Z. Yu, Y. Yuan, S. Wang et al., A new aluminium-ion battery with high voltage, high safety and low cost. Chem. Commun. 51, 11892-11895 (2015). https://doi. org/10.1039/C5CC00542F

6. Z. Li, B. Niu, J. Liu, J. Li, F. Kang, Rechargeable aluminumion battery based on $\mathrm{MoS}_{2}$ microsphere cathode. ACS Appl. Mater. Interfaces 10(11), 9451-9459 (2018). https://doi.org/ 10.1021/acsami.8b00100

7. K. Zhang, K.O. Kirlikovali, J.M. Suh, J.W. Choi, H.W. Jang et al., Recent advances in rechargeable aluminum-ion batteries and considerations for their future progress. ACS Appl. Energy Mater. 3(7), 6019-6035 (2020). https://doi.org/10. 1021/acsaem.0c00957

8. X. Dong, H. Xu, H. Chen, L. Wang, J. Wang et al., Commercial expanded graphite as high-performance cathode for low-cost aluminum-ion battery. Carbon 148, 134-140 (2019). https://doi.org/10.1016/j.carbon.2019.03.080

9. J.V. Rani, V. Kanakaiah, T. Dadmal, M.S. Rao, S. Bhavanarushi et al., Fluorinated natural graphite cathode for rechargeable ionic liquid based aluminum-ion battery. Society 160(10), A1781-A1784 (2013). https://doi.org/10.1149/2. 072310jes

10. R.D. Mckerracher, A. Holland, A. Cruden, R.G.A. Wills, Comparison of carbon materials as cathodes for the aluminium-ion battery. Carbon 144, 333-341 (2019). https://doi.org/ 10.1016/j.carbon.2018.12.021

11. K.V. Kravchyk, M.V. Kovalenko, Rechargeable dual-ion batteries with graphite as a cathode: key challenges and opportunities. Adv. Energy Mater. 9(35), 1901749 (2019). https://doi. org/10.1002/aenm.201901749 
12. S.K. Das, S. Mahapatra, H. Lahan, Aluminium-ion batteries: developments and challenges. J. Mater. Chem. A 5, 6347-6367 (2017). https://doi.org/10.1039/C7TA00228A

13. C. Wu, S. Gu, Q. Zhang, Y. Bai, M. Li et al., Electrochemically activated spinel manganese oxide for rechargeable aqueous aluminum battery. Nat. Commun. 10, 73 (2019). https://doi. org/10.1038/s41467-018-07980-7

14. W. Yang, H. Lu, Y. Cao, P. Jing, Single-/few-layered ultrasmall $\mathrm{WS}_{2}$ nanoplates embedded in nitrogen-doped carbon nanofibers as a cathode for rechargeable aluminum batteries. J. Power Source 441, 227173 (2019). https://doi.org/10.1016/j.jpows our.2019.227173

15. W. Yang, H. Lu, Y. Cao, B. Xu, Y. Deng et al., Flexible free-standing $\mathrm{MoS}_{2}$ /carbon nanofibers composite cathode for rechargeable aluminum-ion batteries. ACS Sustain. Chem. Eng. 7, 4861-4867 (2019). https://doi.org/10.1021/acssu schemeng.8b05292

16. W. Yang, H. Lu, Y. Cao, P. Jing, X. Hu et al., A flexible freestanding cathode based on graphene-like $\mathrm{MoSe}_{2}$ nanosheets anchored on $\mathrm{N}$-doped carbon nanofibers for rechargeable aluminum-ion batteries. Ionics 26, 3405-3413 (2020). https://doi.org/10.1007/s11581-020-03476-x

17. N.S. Hudak, Chloroaluminate-doped conducting polymers as positive electrodes in rechargeable aluminum batteries. J. Phys. Chem. C 118(10), 5203-5215 (2014). https://doi.org/ 10.1021/jp500593d

18. H. Chen, F. Guo, Y. Liu, T. Huang, B. Zheng et al., A defectfree principle for advanced graphene cathode of aluminumion battery. Adv. Mater. 29(12), 1605958 (2017). https://doi. org/10.1002/adma.201605958

19. X. Yu, B. Wang, D. Gong, Z. Xu, B. Lu, Graphene nanoribbons on highly porous 3D graphene for high-capacity and ultrastable al-ion batteries. Adv. Mater. 29(4), 1604118 (2017). https://doi.org/10.1002/adma.201604118

20. H. Chen, C. Chen, Y. Liu, X. Zhao, N. Ananth et al., Highquality graphene microflower design for high-performance Li-S and Al-Ion batteries. Adv. Energy Mater. 7(17), 1700051 (2017). https://doi.org/10.1002/aenm.201700051

21. D.Y. Wang, C.Y. Wei, M.C. Lin, C.J. Pan, H.L. Chou et al., Advanced rechargeable aluminium ion battery with a highquality natural graphite cathode. Nat. Commun. 8, 14283 (2017). https://doi.org/10.1038/ncomms 14283

22. D.H. Hu, T. Cai, P. Bai, J. Xu, S. Ge et al., Small graphite nanoflakes as an advanced cathode material for aluminum ion batteries. Chem. Commun. 56, 1593-1596 (2020). https://doi.org/10.1039/C9CC06895C

23. N.P. Stadie, S. Wang, K.V. Kravchyk, M.V. Kovalenko, Zeolite-templated carbon as an ordered microporous electrode for aluminum batteries. ACS Nano 11(2), 1911-1919 (2017). https://doi.org/10.1021/acsnano.6b07995

24. Q. Zhang, L. Wang, J. Wang, C. Xing, J. Ge et al., Lowtemperature synthesis of edge-rich graphene paper for highperformance aluminum batteries. Energy Storage Mater. 15, 361-367 (2018). https://doi.org/10.1016/j.ensm.2018.06.021
25. Z. Liu, J. Wang, H. Ding, S. Chen, X. Yu et al., Carbon nanoscrolls for aluminum battery. ACS Nano 12(8), 84568466 (2018). https://doi.org/10.1021/acsnano.8b03961

26. Y. Uemura, C.Y. Chen, Y. Hashimoto, T. Tsuda, H. Matsumoto et al., Graphene nanoplatelet composite cathode for a chloroaluminate ionic liquid-based aluminum secondary battery. ACS Appl. Energy Mater. 1(5), 2269-2274 (2018). https://doi.org/10.1021/acsaem.8b00341

27. K.L. Ng, T. Dong, J. Anawati, G. Azimi, High-performance aluminum ion battery using cost-effective $\mathrm{AlCl}_{3}$-trimethylamine hydrochloride ionic liquid electrolyte. Adv. Sustain. Syst. 4(8), 2000074 (2020). https://doi.org/10. 1002/adsu.202000074

28. G.A. Elia, J.B. Ducros, D. Sotta, V. Delhorbe, A. Brun et al., Polyacrylonitrile separator for high-performance aluminum batteries with improved interface stability. ACS Appl. Mater. Interfaces 9(44), 38381 (2017). https://doi.org/10. 1021/acsami.7b09378

29. M. Walter, K.V. Kravchyk, C. Böfer, R. Widmer, M.V. Kovalenko, Polypyrenes as high-performance cathode materials for aluminum batteries. Adv. Mater. 30(15), 1705644 (2018). https://doi.org/10.1002/adma.201705644

30. D.J. Kim, D.J. Yoo, M.T. Otley, A. Prokofjevs, C. Pezzato et al., Rechargeable aluminium organic batteries. Nat. Energy 4, 51-59 (2019). https://doi.org/10.1038/ s41560-018-0291-0

31. D. Lee, G. Lee, Y. Tak, Hypostatic instability of aluminum anode in acidic ionic liquid for aluminum-ion battery. Nanotechnology 29, 36LT01 (2018). https://doi.org/10.1088/ 1361-6528/aacd7f

32. C. Li, J. Patra, J. Li, P.C. Rath, M.H. Lin et al., A novel moisture-insensitive and low-corrosivity ionic liquid electrolyte for rechargeable aluminum batteries. Adv. Funct. Mater. 30(12), 1909565 (2020). https://doi.org/10.1002/ adfm.201909565

33. Y. Shin, S. Jung, I. Jeon, J. Baek, The oxidation mechanism of highly ordered pyrolytic graphite in a nitric acid/sulfuric acid mixture. Carbon 52, 493-498 (2013). https://doi.org/10. 1016/j.carbon.2012.10.001

34. Z. Zhang, J. Xi, H. Zhou, X. Qiu, The oxidation mechanism of highly ordered pyrolytic graphite in a nitric acid/sulfuric acid mixture. Electrochim. Acta 218(10), 15-23 (2016). https://doi. org/10.1016/j.electacta.2016.09.099

35. Q. Cheng, R. Yuge, K. Nakahara, N. Tamura, S. Miyamoto, $\mathrm{KOH}$ etched graphite for fast chargeable lithium-ion batteries. J. Power Sources 284, 258-263 (2015). https://doi.org/10. 1016/j.jpowsour.2015.03.036

36. J.H. Shim, S. Lee, Characterization of graphite etched with potassium hydroxide and its application in fast-rechargeable lithium ion batteries. J. Power Sources 324, 475-483 (2016). https://doi.org/10.1016/j.jpowsour.2016.05.094

37. J. Kim, S.M.N. Jeghan, G. Lee, Superior fast-charging capability of graphite anode via facile surface treatment for 
lithium-ion batteries. Micropor. Mesopor. Mat. 305, 110325 (2020). https://doi.org/10.1016/j.micromeso.2020.110325

38. Z.Q. Li, C.J. Lu, Z.P. Xia, Y. Zhou, Z. Luo, X-ray diffraction patterns of graphite and turbostratic carbon. Carbon 45(8), 1686-1695 (2007). https://doi.org/10.1016/j.carbon.2007.03. 038

39. P. Tatarko, S. Grasso, T.G. Saunders, V. Casalegno, M. Ferraris et al., Flash joining of CVD-SiC coated $\mathrm{Cf} / \mathrm{SiC}$ composites with a Ti interlayer. J. Eur. Ceram. 37(13), 3841-3848 (2017). https://doi.org/10.1016/j.jeurceramsoc.2017.05.016

40. T. Qiu, J. Yang, X. Bai, Y. Wang, The preparation of synthetic graphite materials with hierarchical pores from lignite by one-step impregnation and their characterization as dye absorbents. RSC Adv. 9(22), 12737-12746 (2019). https://doi. org/10.1039/C9RA00343F

41. N. Iwashita, C.R. Park, H. Fujimoto, M. Shiraishi, M. Inagaki, Specification for a standard procedure of X-ray diffraction measurements on carbon materials. Carbon 42(4), 7-14 (2004). https://doi.org/10.1016/j.carbon.2004.02.008

42. J. Sottmann, M. Herrmann, P. Vajeeston, Y. Hu, A. Ruud et al., How crystallite size controls the reaction path in nonaqueous metal ion batteries: the example of sodium bismuth alloying. Chem. Mater. 28(8), 2750-2756 (2016). https://doi.org/10.1021/ acs.chemmater.6b00491

43. D. Son, J. Kim, M.R. Raj, G. Lee, Elucidating the structural redox behaviors of nanostructured expanded graphite anodes toward fast-charging and high-performance lithium-ion batteries. Carbon 175, 187-201 (2021). https://doi.org/10.1016/j.carbon. 2021.01.015

44. D. Jung, J. Jeong, B. Cha, J. Kim, B. Kong et al., Effects of ballmilled graphite in the synthesis of $\mathrm{SnO}_{2}$ /graphite as an active material in lithium ion batteries. Met. Mater. Int. 17, 1021-1026 (2011). https://doi.org/10.1007/s12540-011-6022-8

45. S. Roscher, R. Hoffmann, O. Ambacher, Determination of the graphene-graphite ratio of graphene powder by Raman 2D band symmetry analysis. Anal. Methods 11(9), 1224-1228 (2019). https://doi.org/10.1039/C8AY02619J

46. K.S. Munir, M. Qian, Y. Li, D.T. Oldfield, P. Kingshott et al., Quantitative analyses of MWCNT-Ti powder mixtures using raman spectroscopy: the influence of milling parameters on nanostructural evolution. Adv. Eng. Mater. 17(11), 16601669 (2015). https://doi.org/10.1002/adem.201500142

47. G. Leofantia, M. Padovan, G. Tozzola, B. Venturelli, Surface area and pore texture of catalysts. Catal. Today 41(1-3), 207219 (1998). https://doi.org/10.1016/S0920-5861(98)00050-9

48. C. Zhu, S. Guo, Y. Fang, S. Dong, Reducing sugar: new functional molecules for the green synthesis of graphene nanosheets. ACS Nano 4(4), 2429-2437 (2010). https://doi.org/10.1021/ nn1002387

49. K. Batra, S. Nayak, S.K. Behura, O. Jani, Optimizing performance parameters of chemically-derived graphene/p-Si heterojunction solar cell. J. Nanosci. 15(7), 4877-4882 (2015). https:// doi.org/10.1166/jnn.2015.9818

50. Y. Wu, C. Jiang, C. Wan, E. Tsuchida, Effects of catalytic oxidation on the electrochemical performance of common natural graphite as an anode material for lithium ion batteries.
Electrochem. Commun. 2(4), 272-275 (2000). https://doi.org/ 10.1016/S1388-2481(00)00022-9

51. C. Xu, X. Shi, A. Ji, L. Shi, C. Zhou et al., Fabrication and characteristics of reduced graphene oxide produced with different green reductants. PLoS ONE 10, e0144842 (2015). https://doi. org/10.1371/journal.pone.0144842

52. M. Yi, Z. Shen, S. Liang, L. Liu, X. Zhang et al., Water can stably disperse liquid-exfoliated graphene. Chem. Commun. 49, 11059-11061 (2013). https://doi.org/10.1039/C3CC46457A

53. K.V. Kravchyk, S. Wang, L. Piveteau, M.V. Kovalenko, Efficient aluminum chloride-natural graphite battery. Chem. Mater. 29(10), 4484-4492 (2017). https://doi.org/10.1021/acs.chemm ater.7b01060

54. K.V. Kravchyk, M.V. Kovalenko, Aluminum electrolytes for Al dual-ion batteries. Commun. Chem. 3, 120 (2020). https://doi. org/10.1038/s42004-020-00365-2

55. L. Somerville, J. Bareno, S. Trask, P. Jennings, A. McGordon et al., The effect of charging rate on the graphite electrode of commercial lithium-ion cells: a post-mortem study. J. Power Sources 335, 189-196 (2016). https://doi.org/10.1016/j.jpowsour.2016.10. 002

56. J. Smajic, A. Alazmi, N. Batra, T. Palanisamy, D.H. Anjum et al., Mesoporous reduced graphene oxide as a high capacity cathode for aluminum batteries. Small 14(51), 1803584 (2018). https:// doi.org/10.1002/smll.201803584

57. S. Wang, K.V. Kravchyk, F. Krumeich, M.V. Kovalenko, Kish graphite flakes as a cathode material for an aluminum chloridegraphite battery. ACS Appl. Mater. Interfaces 9(34), 2847828485 (2017). https://doi.org/10.1021/acsami.7b07499

58. P. Simon, Y. Gogotsi, B. Dunn, Where do batteries end and supercapacitors begin? Science 343(6176), 1210-1211 (2014). https://doi.org/10.1126/science.1249625

59. Y. Lan, H. Zhao, Y. Zong, X. Li, Y. Sun et al., Phosphorization boosts the capacitance of mixed metal nanosheet arrays for high performance supercapacitor electrodes. Nanoscale 10, 11775 (2018). https://doi.org/10.1039/C8NR01229F

60. T. Brezesinski, J. Wang, J. Polleux, B. Dunn, S.H. Tolbert, Templated nanocrystal-based porous $\mathrm{TiO}_{2}$ Films for next-generation electrochemical capacitors. J. Am. Chem. Soc. 131(5), 18021809 (2009). https://doi.org/10.1021/ja8057309

61. L. Wu, J. Lang, P. Zhang, X. Zhang, R. Guo et al., Mesoporous $\mathrm{Ni}$-doped $\mathrm{MnCo}_{2} \mathrm{O}_{4}$ hollow nanotubes as an anode material for sodium ion batteries with ultralong life and pseudocapacitive mechanism. J. Mater. Chem. A 4, 18392-18400 (2016). https:// doi.org/10.1039/C6TA08364A

62. J. Wang, J. Polleux, J. Lim, B. Dunn, Pseudocapacitive contributions to electrochemical energy storage in $\mathrm{TiO}_{2}$ (Anatase) nanoparticles. J. Phys. Chem. C 111(40), 14925-14931 (2007). https://doi.org/10.1021/jp074464w

63. T. Brezesinski, J. Wang, S.H. Tolbert, B. Dunn, Ordered mesoporous $\alpha-\mathrm{MoO}_{3}$ with iso-oriented nanocrystalline walls for thin-film pseudocapacitors. Nat. Mater. 9, 146-151 (2010). https://doi.org/10.1038/nmat2612

64. W. Liu, H. Niu, J. Yang, K. Cheng, K. Ye et al., Ternary transition metal sulfides embedded in graphene nanosheets as both 
the anode and cathode for high-performance asymmetric supercapacitors. Chem. Mater. 30(3), 1055-1068 (2018). https://doi. org/10.1021/acs.chemmater.7b04976

65. T. Cai, L. Zhao, H. Hu, T. Li, X. Li et al., Stable $\mathrm{CoSe}_{2} /$ carbon nanodice@reduced graphene oxide composites for high-performance rechargeable aluminum-ion batteries. Energy Environ. Sci. 11, 2341-2347 (2018). https://doi.org/10.1039/C8EE00822A

66. Y. Zhu, J. Wang, F. Zhang, S. Gao, A. Wang et al., Zwitterionic nanohydrogel grafted PVDF membranes with comprehensive antifouling property and superior cycle stability for oil-in-water emulsion separation. Adv. Funct. Mater. 28(40), 1804121 (2018). https://doi.org/10.1002/adfm.201804121

67. W. Pan, Y. Wang, Y. Zhang, H.Y.H. Kwok, M. Wu et al., A low-cost and dendrite-free rechargeable aluminium-ion battery with superior performance. J. Mater. Chem. A 7, 17420-17425 (2019). https://doi.org/10.1039/C9TA05207K

68. S. Wang, S. Jiao, W. Song, H. Chen, J. Tu et al., A novel dual-graphite aluminum-ion battery. Energy Storage Mater. 12, 119-127 (2018). https://doi.org/10.1016/j.ensm.2017.12. 010 